Prepared for the U.S. Department of Energy under Contract DE-AC05-76RL01830

\title{
Leadership and Stewardship of the Laboratory (Objective 4.1) Notable Outcome - Phase II Alternative Analysis and PNNL Site Plan Recommendation
}

N2013-1.3-RPT-PII-01, Revision 0
JP Pittman
SR Cassidy
WC Mosey
EM Leitz
LJ Oukrop

July 2013

Pacific Northwest

NATIONAL LABORATORY

Proudly Operated by Battelle Since 1965 


\title{
DISCLAIMER
}

This report was prepared as an account of work sponsored by an agency of the United States Government. Neither the United States Government nor any agency thereof, nor Battelle Memorial Institute, nor any of their employees, makes any warranty, express or implied, or assumes any legal liability or responsibility for the accuracy, completeness, or usefulness of any information, apparatus, product, or process disclosed, or represents that its use would not infringe privately owned rights. Reference herein to any specific commercial product, process, or service by trade name, trademark, manufacturer, or otherwise does not necessarily constitute or imply its endorsement, recommendation, or favoring by the United States Government or any agency thereof, or Battelle Memorial Institute. The views and opinions of authors expressed herein do not necessarily state or reflect those of the United States Government or any agency thereof.

\author{
PACIFIC NORTHWEST NATIONAL LABORATORY \\ operated by \\ BATTELLE \\ for the \\ UNITED STATES DEPARTMENT OF ENERGY \\ under Contract DE-AC05-76RL01830
}

Printed in the United States of America
Available to DOE and DOE contractors from the Office of Scientific and Technical Information,
P.O. Box 62, Oak Ridge, TN 37831-0062;
ph: (865) 576-8401
fax: $(865)$ 576-5728
email: reports@adonis.osti.gov

\begin{abstract}
Available to the public from the National Technical Information Service, U.S. Department of Commerce, 5285 Port Royal Rd., Springfield, VA 22161 ph: (800) 553-6847 fax: $(703) 605-6900$ email: orders@ntis.fedworld.gov online ordering: http://www.ntis.gov/ordering.htm
\end{abstract}

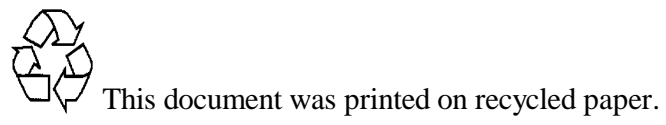




\section{Leadership and Stewardship of the Laboratory (Objective 4.1) Notable Outcome - Phase II Alternative Analysis and PNNL Site Plan Recommendation}

JP Pittman

SR Cassidy

WC Mosey

EM Leitz

LJ Oukrop

July 2013

Prepared for

the U.S. Department of Energy

under Contract DE-AC05-76RL01830

Pacific Northwest National Laboratory

Richland, Washington 99352 


\section{Executive Summary}

Pacific Northwest National Laboratory (PNNL) and the Pacific Northwest Site Office (PNSO) have recently completed an effort to identify the current state of the campus and gaps that exist with regards to space needs, facilities and infrastructure. This effort has been used to establish a campus strategy to ensure PNNL is ready to further the United States (U.S.) Department of Energy (DOE) mission. Ten-year business projections and the impacts on space needs were assessed and incorporated into the long-term facility plans. In identifying/quantifying the space needs for PNNL, the following categories were addressed: Multi-purpose Programmatic (wet chemistry and imaging laboratory space), Strategic (Systems Engineering and Computation Analytics, and Collaboration space), Remediation (space to offset the loss of the Research Technology Laboratory [RTL] Complex due to decontamination and demolition), and Optimization (the exit of older and less cost-effective facilities). The findings of the space assessment indicate a need for wet chemistry space, imaging space, and strategic space needs associated with systems engineering and collaboration space.

Based on the analysis, a 10-year campus strategy evolved that balanced four strategic objectives, as directed by the DOE Office of Science (DOE-SC):

- Mission Alignment - maintain customer satisfaction

- Reasonable \& Achievable - do what makes sense from a practical and cost perspective

- Campus Continuity - increase the federal control of assets and follow the Campus Master Plan

- Guiding Principles - modern, collaborative, flexible, and sustainable.

This strategy considered the following possible approaches to meet the identified space needs:

- Institutional General Plant Project (IGPP) funded projects

- $\quad$ Third party leased facilities

- Science Laboratory Infrastructure (SLI) line item funded projects.

Pairing the four strategic objectives with additional key metrics as criteria for selection, an initial recommendation was made to DOE-SC to use all three funding mechanisms to deliver the mission need. DOE-SC provided feedback that third party facilities are not to be pursued at this time. The decision was made by DOE that an IGPP-funded program would be the base plan, while retaining the possibility of a 2019 SLI-funded project. The SLI project will be designed to deliver significant impact on science and technology (S\&T) and support the development of a modern, synergistic core campus where a collaborative and innovative environment is fostered. The specific scientific impact will be further defined in the 2015 and 2016 Annual Laboratory Plans. Additionally, opportunities will be explored to construct annexes on current federal facilities, including the Environmental Molecular Sciences Laboratory (EMSL), if proven synergistic and cost effective. 
The final result of this effort is an actionable, flexible plan with scope, schedule, and cost targets for individual acquisition projects. Implemented as planned, the result will increase federal ownership by approximately 15 percent, reduce the operating cost by approximately 7 percent, and reduce the geographic facility footprint by approximately 66,000 gross square feet (GSF). Reduction of surplus space will be addressed while maintaining customer satisfaction, lowering operating costs, reducing the campus footprint, and increasing the federal control of assets. This strategy is documented in PNNL's 2014 Laboratory Plan. 


\section{Acronyms and Abbreviations}

\begin{tabular}{|c|c|}
\hline APEL & Applied Process Engineering Laboratory \\
\hline $\mathrm{B} \& \mathrm{U}$ & Building and Utilities \\
\hline BMI & Battelle Memorial Institute \\
\hline $\mathrm{CFC}$ & Cost of Facilities Capital \\
\hline $\mathrm{CFO}$ & chief financial officer \\
\hline D\&D & decommissioning and demolition \\
\hline DOE & U.S. Department of Energy \\
\hline DOE-HQ & DOE Headquarters \\
\hline DOE-SC & DOE Office of Science \\
\hline F\&I & Facilities and Infrastructure \\
\hline FIMS & Facility Information Management System \\
\hline FPS & financial processing system \\
\hline $\mathrm{Ft}^{2}$ & square feet \\
\hline FY & fiscal year \\
\hline GSF & gross square feet \\
\hline IGPP & Institutional General Plant Project \\
\hline LCCA & life cycle cost analysis \\
\hline MARS & Maintenance \& Renewal Forecast System \\
\hline NFSF & net functional square feet \\
\hline NPV & net present value \\
\hline NSF & net square feet \\
\hline O\&M & operations and maintenance \\
\hline OMB & Office of Management and Budget \\
\hline $\mathrm{OPC}$ & other project costs \\
\hline OSD & Operational Systems Directorate \\
\hline
\end{tabular}




$\begin{array}{ll}\text { PEMP } & \text { Performance Evaluation and Measurement Plan } \\ \text { PNNL } & \text { Pacific Northwest National Laboratory } \\ \text { PNSO } & \text { Pacific Northwest Site Office } \\ \text { R\&D } & \text { research and development } \\ \text { REMO } & \text { Real Estate Management Office } \\ \text { RTL } & \text { Research Technology Laboratory } \\ \text { S\&T } & \text { science and technology } \\ \text { SLI } & \text { Science Laboratory Infrastructure } \\ \text { TEC } & \text { total estimated cost } \\ \text { U.S. } & \text { United States } \\ \text { USACE } & \text { United States Army Corps of Engineers } \\ \text { WBS } & \text { work breakdown structure }\end{array}$




\section{Contents}

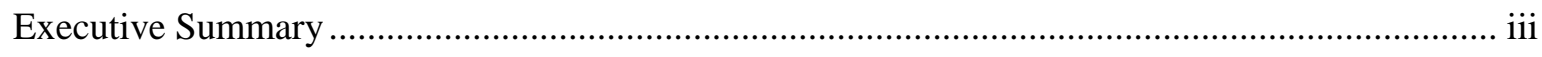

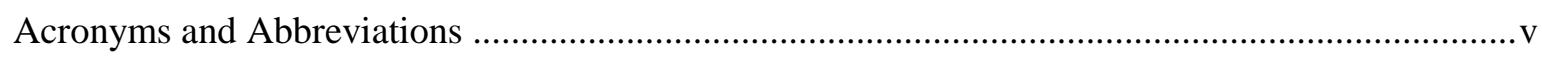

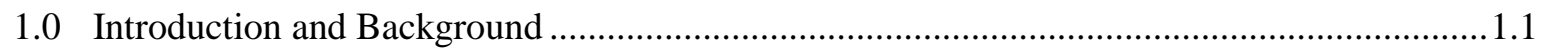

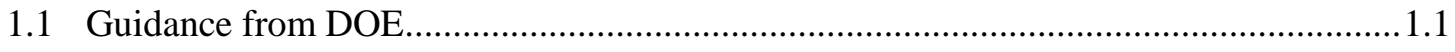

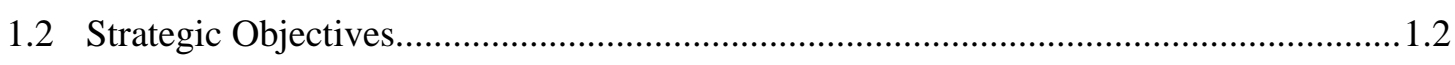

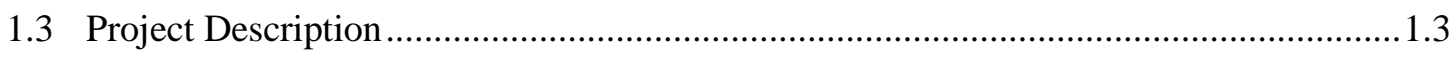

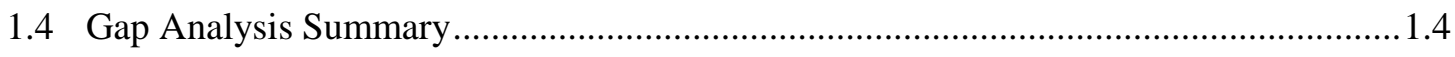

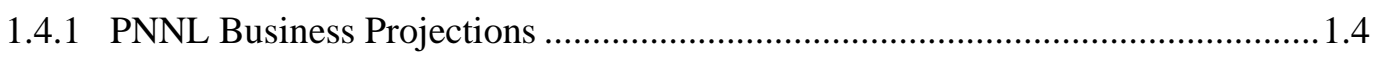

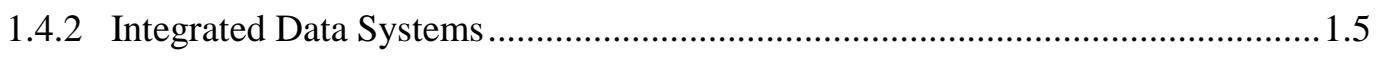

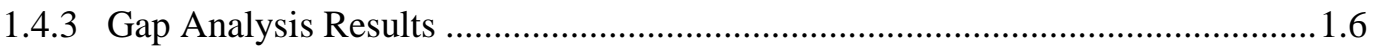

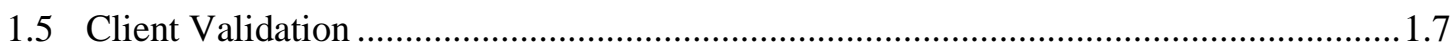

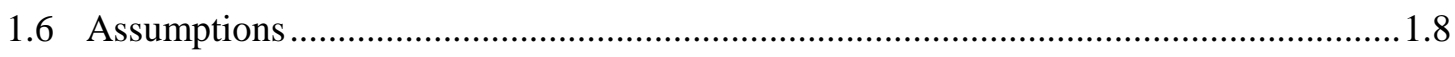

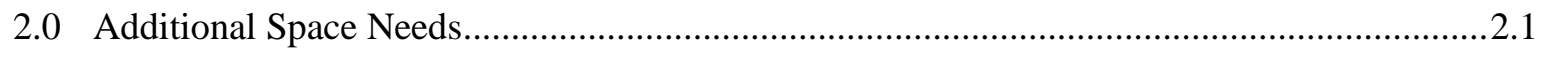

2.1 Contract Requirement (Remediation Impacts) ...................................................... 2.1

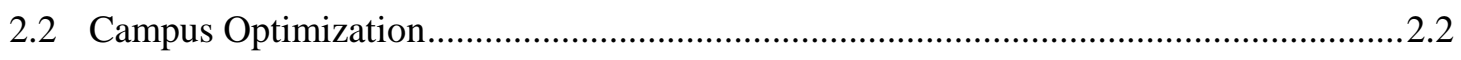

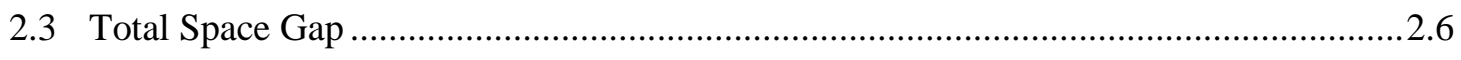

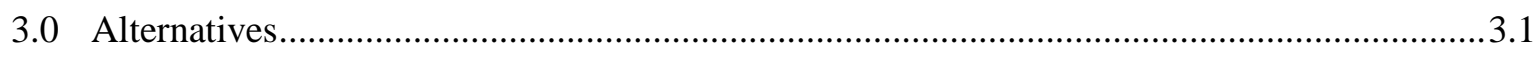

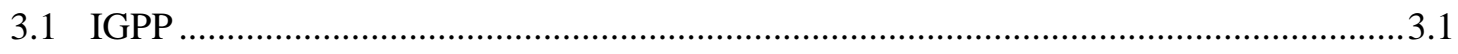

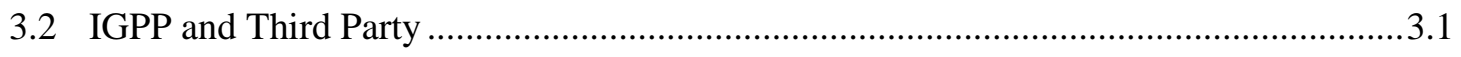

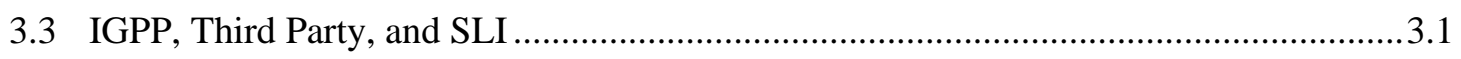

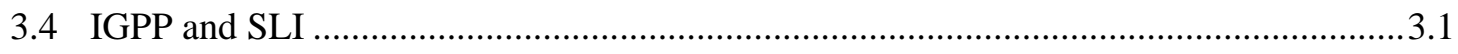

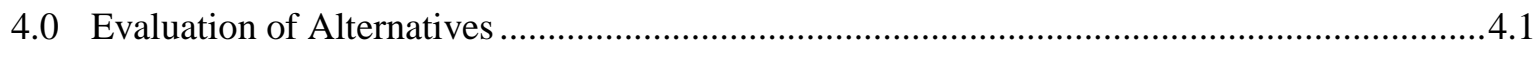

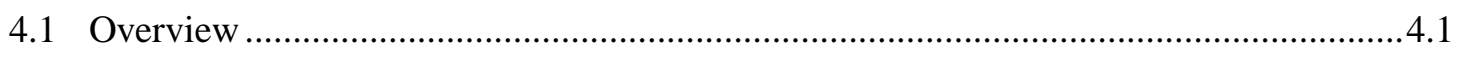

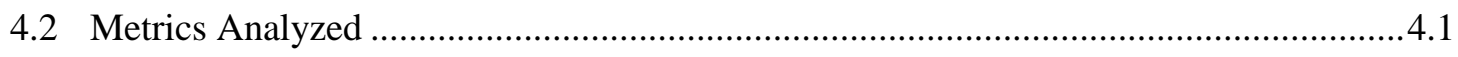

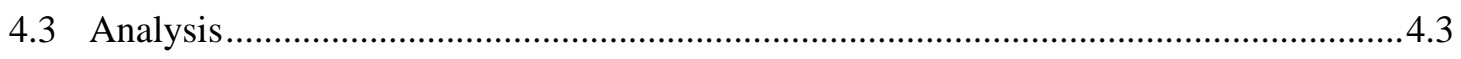

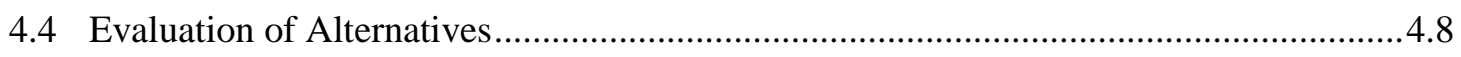

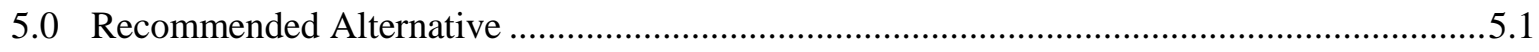

5.1 DOE Recommendation/Feedback ...................................................................... 5.1

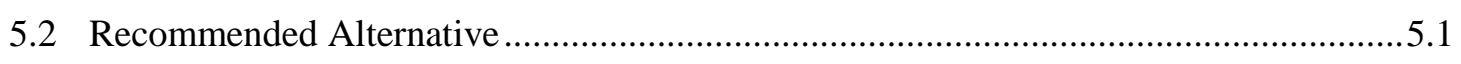

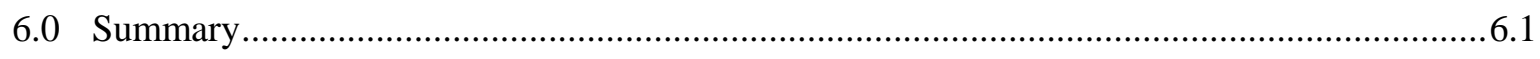

Appendix A Client Validation Profile Sheets ........................................................................... A.1

Appendix B Client Validation of Work Conducted at the Pacific Northwest National Laboratory

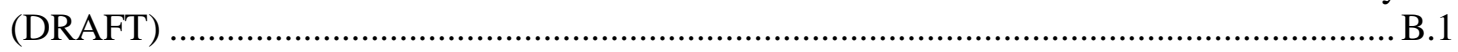

Appendix C Facility Economic Analysis Summary ............................................................... 1

Appendix D Alternative Mass Balance .................................................................................. 1

Appendix E Life Cycle Cost Analysis Methodology ............................................................... E.1

Appendix F Alternative Waterfall Schedules .......................................................................... 1 


\section{Figures}

Figure 1.1. Notable Outcome Project Integrated in Existing Facility Planning Processes ............. 1.1

Figure 1.2. PNNL Site Plan Strategic Objectives ................................................................... 1.2

Figure 1.3. Notable Outcome Work Breakdown Structure ........................................................ 1.3

Figure 1.4. PNNL 10-Year Cost Projections With Historical Conservative Forecasting Results ..1.5

Figure 1.5. Starlight, a PNNL-Developed Visual Analytic Tool, Provides an Image of the Interconnectivity of Our Integrated Capabilities and the Clients that Fund Our Work ............ 1.6

Figure 2.1. Location of RTL on PNNL Campus and the Adjacent New Apartment Complex ......2.1

Figure 2.2. Process for Determining Notable Outcome Cost Per Square Foot .............................2.3

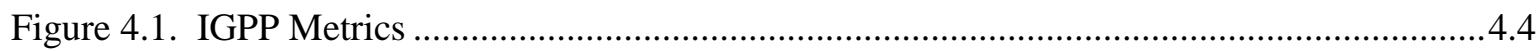

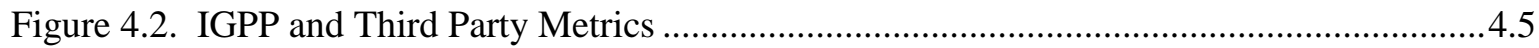

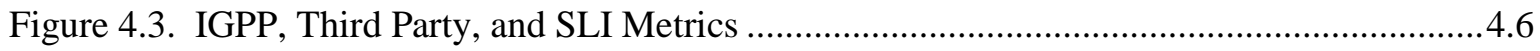

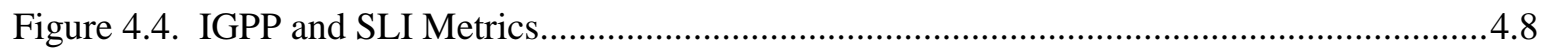

Figure 5.1. DOE Strategy for Lab Plan...................................................................................... 5.1

\section{Tables}

Table 1.1. Gap Analysis Summary Table From Phase I ....................................................... 1.7

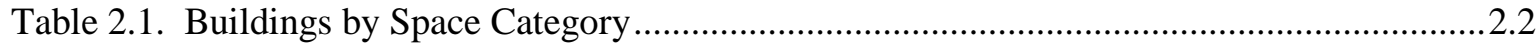

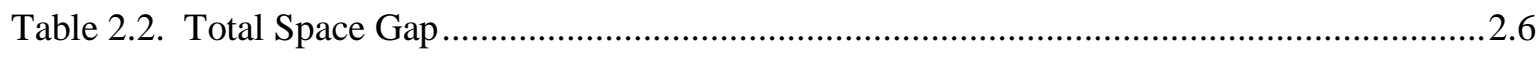

Table 4.1. Life Cycle Cost Analysis Summary ......................................................................... 4.3

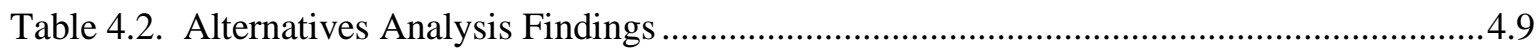




\subsection{Introduction and Background}

\subsection{Guidance from DOE}

DOE-SC initiated an effort in fiscal year (FY) 2013 to develop an expanded and more comprehensive, long-term (10-year) strategic facilities plan for PNNL. This plan was to focus on clarifying the facilities use at PNNL and the future needs for these facilities, as informed by government clients that use the Laboratory, given their forecasts of long-term need for the type of work performed at PNNL.

This DOE-SC initiative was incorporated into the PNNL contract through the creation of the Performance Evaluation and Measurement Plan (PEMP) Notable Outcome (see DOE-Battelle Prime Contract for the Management and Operation of Pacific Northwest National Laboratory DE-AC0576RL01830, Appendix E, Standards of Performance-Based Fee, section 4.3), "Develop a site plan for PNNL, including specifically addressing customers, usage, and requirements." Figure 1.1 illustrates how the results of the Notable Outcome are integrated into the Laboratory's facilities and infrastructure planning processes and DOE-SC's annual Laboratory planning process.

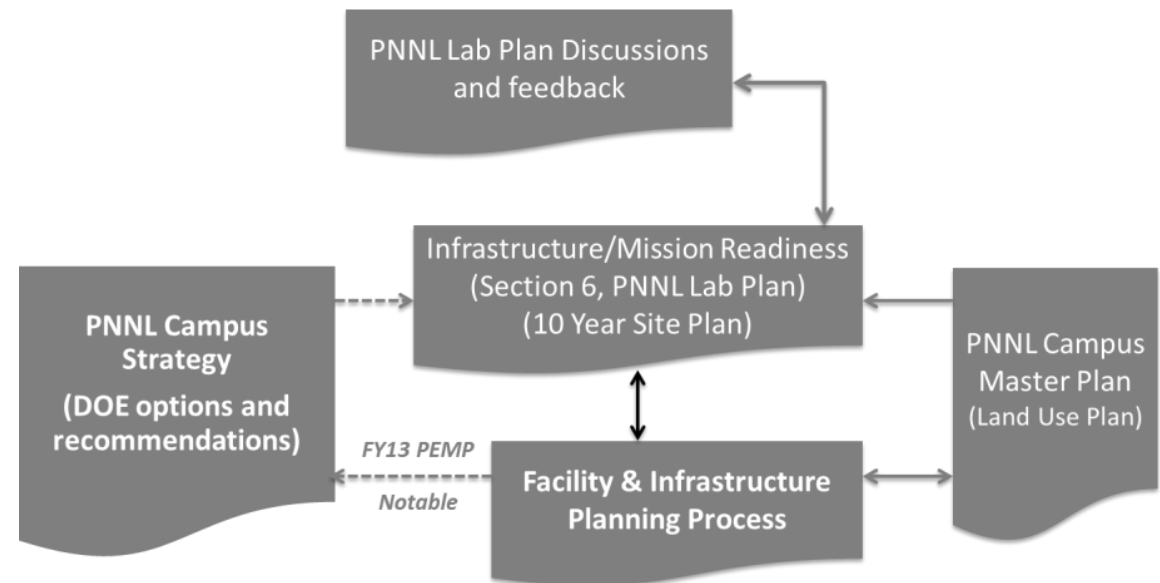

Figure 1.1. Notable Outcome Project Integrated in Existing Facility Planning Processes

In partnership, DOE-SC and PNNL established four strategic objectives to guide the development of the plan for acquiring and sustaining critical PNNL facilities and infrastructure to further the DOE mission. These objectives are Mission Alignment, be Reasonable \& Achievable, Campus Continuity, and follow the Campus Master Plan Guiding Principles. These are discussed further in section 1.2. IGPPs and SLI were the funding mechanisms identified as bounding conditions for evaluating viable alternatives associated with addressing the mission needs in a timely manner. Although third party leases were initially included as an option in the bounding conditions, DOE-SC determined that alternative should not be pursued at this time.

The scope was limited to PNNL Richland-campus facilities only, excluding the 300 Area and Marine Sciences Laboratory facilities. This was affirmed in a meeting on March 5, 2013 with PNSO. 


\subsection{Strategic Objectives}

As stated previously, the facility strategy must balance four strategic objectives. Figure 1.2 summarizes the strategic objectives and bounding conditions agreed to with PNSO and DOE-SC at the conclusion of the Gap Analysis presentation in January 2013.

\begin{tabular}{|c|c|}
\hline \multicolumn{2}{|c|}{$\begin{array}{l}\text { PNSO applied DOE-SC guidance to } \\
\text { meet the strategic objectives }\end{array}$} \\
\hline \multicolumn{2}{|c|}{ Mission Alignment } \\
\hline Maintain customer satisfaction & $\begin{array}{l}\text { Funding conditions } \\
\text { bound scenarios }\end{array}$ \\
\hline Reasonable \& Achievable & - IGPP $<\$ 10 M$ \\
\hline $\begin{array}{l}\text { Do what makes sense from a practical } \\
\text { and cost perspective }\end{array}$ & $\begin{array}{l}\cdot 3^{\text {ro }} \text { Party Lease } \\
\$ 50 \mathrm{M}\end{array}$ \\
\hline Campus Continuity & $\begin{array}{l}\text { - SLI } \$ 50 \mathrm{Mnot} \\
\text { before } 2019\end{array}$ \\
\hline $\begin{array}{l}\text { Withdraw from BMI buildings over time } \\
\text { (emphasis on increasing Federal control of assets) }\end{array}$ & \\
\hline \multicolumn{2}{|l|}{ Campus Master Plan Guiding Principles } \\
\hline $\begin{array}{l}\text { Ensure a mission-ready campus that is moder } \\
\text { flexible, and sustainable }\end{array}$ & aborative, \\
\hline
\end{tabular}

Figure 1.2. PNNL Site Plan Strategic Objectives

A more detailed explanation of each of those objectives is described below.

\section{Mission Alignment}

This objective involves validating that campus investment plans are aligned to meet the scientific mission of the Lab. The scope incorporates three areas specific to mission-aligned facilities. The first includes needs identified by research to support the clients. The second incorporates strategic needs identified by the Laboratory leadership team. Finally, the objective incorporates the need to provide a functional space inventory and surplus space reduction.

\section{Reasonable/Achievable}

This objective focuses on developing an achievable plan, given current financial conditions and realistic projections. The strategy is bounded by a 10 -year investment period and includes a total operating cost evaluation over a 30 -year study period.

\section{Campus Continuity}

This objective emphasizes increasing the federal footprint and federal control of assets on the PNNL campus. It is aimed at reducing the quantity Battelle Memorial Institute (BMI) owned facilities over time and provides an improved environment for contract competition. 


\section{Campus Master Plan Guiding Principles}

This objective verifies the guiding principles agreed to by PNSO and PNNL in the September 2012 Campus Master Plan will be used to develop and invest in the future campus. The guiding principles are modern, collaborative, flexible, and sustainable. A detailed description can be found in the PNNL Campus Master Plan. ${ }^{1}$

\subsection{Project Description}

A phased approach was used to accomplish the PEMP Notable Outcome. Phase I identified gaps associated with the client-forecasted needs and is documented in the gap analysis presentation delivered to DOE Headquarters (DOE-HQ) January 29, 2013. Phase II incorporated the Phase I gaps and additional space needs, and developed and evaluated acquisition scenarios to meet the identified space needs over the next 10 years. Included in Phase II is the quantification of overall space needs (i.e., net laboratory space, common space, and other space types resulting in an overall GSF amount), parametric cost estimates for the various scenarios, and preliminary schedule logic for scenario implementation. The evaluation of these scenarios (i.e., alternatives analysis) resulted in the preferred subset of actions that comprise the PNNL Site Plan documented in the 2014 Laboratory Plan as the Facilities and Infrastructure (F\&I) Strategy.

A project was chartered to complete the work, and the project work breakdown structure (WBS) is presented below in Figure 1.3.

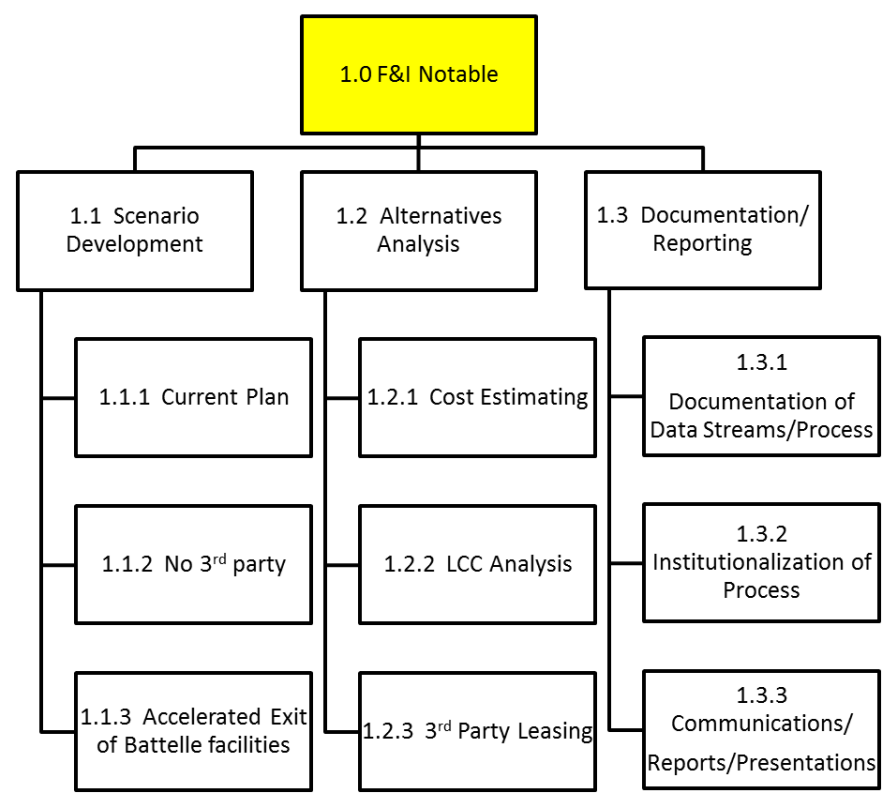

Figure 1.3. Notable Outcome Work Breakdown Structure

\footnotetext{
${ }^{1}$ https://collaborate.pnl.gov/projects/facilitiescontent/SiteAssets/Home_Page/Campus_Master_Plan.pdf (PNNL21700, rev.0)
} 


\section{Project Objectives and Deliverables (Key Performance Parameters)}

Each WBS element is responsible for key deliverables that contribute to the overall success of the project. Those deliverables are summarized below:

- Document the data streams and process used to deliver the information for Phase I, including a plan to institutionalize the results and methodologies into PNNL's space management process.

- Develop scenarios with the ability to meet the identified space gap via the available funding mechanisms through a combination of existing and new facility additions (i.e., new construction, renovation of existing space [either Battelle-owned facilities or DOE-owned facilities], additions to or renovation of existing third party leased facilities, and/or newly leased third party facilities). The scenarios will generally be characterized by scope (square feet $\left[\mathrm{ft}^{2}\right]$ by space type) initial cost, life cycle cost, and acquisition schedule.

- Perform an analysis of those scenarios in accordance with the consensus criteria.

- Provide a final report (this document).

- Deliver a PowerPoint presentation (about 20 slides) summarizing the project, process, and outcomes (delivered to DOE-SC by PNSO on April 9, 2013).

- Provide input to the 2014 Laboratory Plan, section 6.0, "Infrastructure/Mission Readiness" (submitted to DOE-SC on May 2,2013).

\subsection{Gap Analysis Summary}

This section summarizes the results in Phase I that were presented to DOE-SC on January 29, 2013.

\subsubsection{PNNL Business Projections}

A 10-year business forecast was developed based on programmatic information received from the clients. The typical business planning process is based on a 5-year projection and has historically been conservative with a clear alignment of trends (e.g., increases or decreases), providing confidence in the use of these data. An additional 5-year projection (FY 2019-2023) was requested. Figure 1.4 represents the 5-year actual and 10-year forecasted internal and external costs. The results indicated a stable business environment that remains flat for the next 10 years. In Figure 1.4, the "FY 2007 Internal Cost Estimate" line is the 5-year client projection calculated in FY 2007, which is below the actual realized cost. 


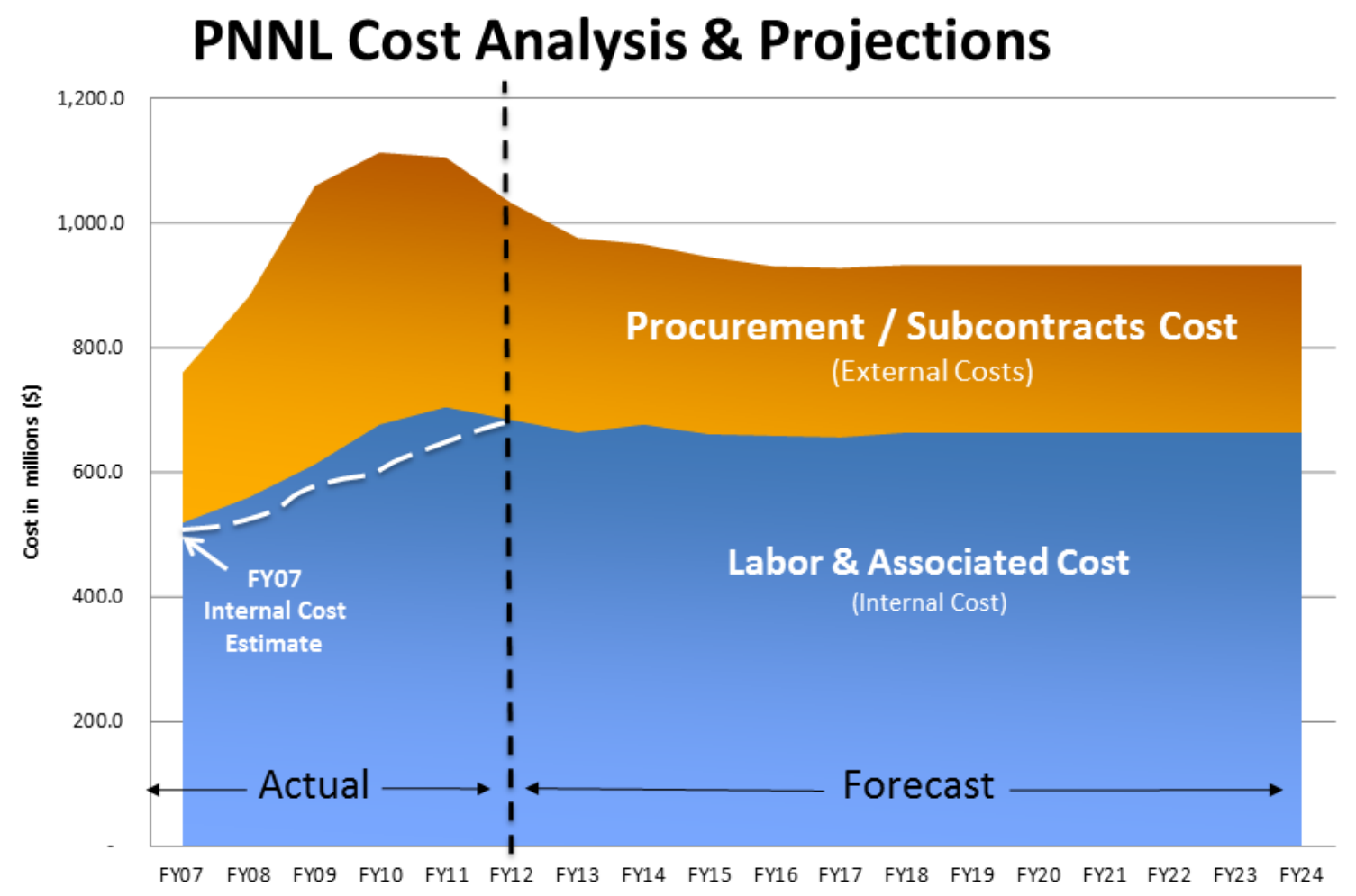

Figure 1.4. PNNL 10-Year Cost Projections With Historical Conservative Forecasting Results

\subsubsection{Integrated Data Systems}

A creative approach was used to quantitatively define the current use and existing gap in the type of space on the PNNL campus. Three existing data systems were integrated to connect people and the project(s) they are working on to the core capabilities, to the lab space(s) they work in, and the specific client(s) they support. The Financial Processing System provided employee's time (FTE), with cost incurred on a project charged to a client. The Integrated Operations System provided employee's access to lab spaces. The Facility Information System provided facility inventory (i.e., type of space, gross square footage, functionality, and core capability). Starlight, a PNNL-developed visual analytic tool, was used to analyze the interconnectivity of PNNL's staff, facilities, type of space, core capabilities, and clients - one of the views can be seen in Figure 1.5. Integrating the data systems allowed for the amount of functional space, along with the current use, to be defined and analyzed. The client projections were overlaid on the current use to define the future projected needs. Integrating existing data systems allowed for the current and future gap to be quantitatively defined. 


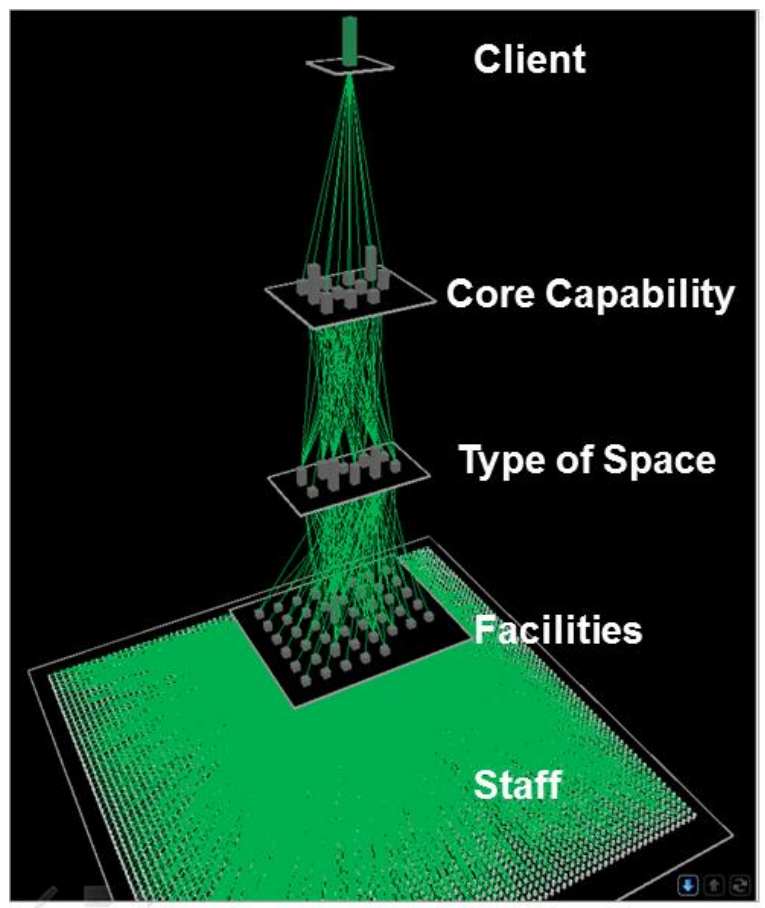

Figure 1.5. Starlight, a PNNL-Developed Visual Analytic Tool, Provides an Image of the Interconnectivity of Our Integrated Capabilities and the Clients that Fund Our Work

This integrated view provided information on how the facilities and spaces are used across the campus and to what magnitude each is used in support of client work. It also provided a clear understanding of the amount of facility space currently existing at PNNL.

\subsubsection{Gap Analysis Results}

Multi-purpose Programmatic - A systematic review of customer forecasts, current space usage, and surplus space over a 10-year period identified a gap in wet chemistry and imaging space. The gap is based on a relatively flat customer forecast from FY 2014 through FY 2023 and was validated by DOE through an independent review of customer forecasted needs. Needs, both current and projected, were defined by integrating existing data from space inventory, time charging, and project financial systems. In addition, merging the client forecasted needs over a 10-year period resulted in a comprehensive understanding of the mission gaps to include types of needed space, as well as surplus space.

Strategic - Facility capabilities identified as strategic investments supporting Laboratory major initiatives and core capabilities were incorporated into the gap analysis. For example, the Efficient and Secure Electricity Management major initiative identified the combination of systems engineering and computational analytic space as a needed facility capability not currently available within the existing portfolio. Laboratory leadership is championing the strategic development of flexible onsite S\&T collaborative meeting space, services and amenities, and a prominent and centralized point of entry into the Laboratory, which would support capabilities across PNNL. These two strategic capability needs add to the mission gap.

Defining the gap in terms of mission alignment verifies that facilities will be available to meet the needs of research. Two space types, wet chemistry and imaging, were identified as needed gaps in space. 
The gap also includes surplus of space based on current use and projected needs. Table 1.1 summarizes the gap—-both surplus and needs.

Table 1.1. Gap Analysis Summary Table From Phase I

\begin{tabular}{|c|c|c|c|c|}
\hline \multirow{3}{*}{ Space Type } & \multirow[t]{2}{*}{ Current } & \multirow{2}{*}{$\begin{array}{c}\text { Projected } \\
\text { Need }\end{array}$} & \multicolumn{2}{|c|}{ Gap } \\
\hline & & & Surplus & Need \\
\hline & \multicolumn{4}{|c|}{ Functional Square Feet (K) } \\
\hline Office & 629 & 576 & 53 & \\
\hline \multicolumn{5}{|l|}{ Chemistry/Materials } \\
\hline - Radiological & 18 & 14 & 4 & \\
\hline - Non-Radiological & 57 & 71 & & 14 \\
\hline Biological/Procedure & 99 & 76 & 23 & \\
\hline Instrumentation & 156 & 145 & 11 & \\
\hline Lab Support & 71 & 63 & 8 & \\
\hline Computational & 56 & 54 & & \\
\hline \multicolumn{5}{|l|}{ Other } \\
\hline - Imaging & 3 & 8 & & 5 \\
\hline - Other & 62 & 53 & 9 & \\
\hline
\end{tabular}

The wet chemistry need of 14,000 net square feet (NSF) is a current year, FY 2013, need for space. Two imaging cells, 1,200 net square feet, are needed by the end of 2017, with the remaining 3,800 NSF needed by 2020 .

\subsection{Client Validation}

One of the major inputs to define PNNL's projected space needs was the 10-year business projections for each major client (i.e., DOE-SC, DOE Energy, NNSA, etc.). These projections came from PNNL's client relationship managers (i.e., sector managers) and were translated to space based on the type of space they were currently using. It was later validated that the type of space used in the future would not change substantially from what they are using now. With that understanding, the complete mission alignment gap was defined. Client profile sheets were used to facilitate discussions with clients and included information on the core capabilities, the type of space, amount of funding, and the forecast for key programs specific to the client. This provided a greater understanding on the impact of the client at PNNL. An example client profile sheet can be found in Appendix A.

The validation of PNNL's 10-year business projections was conducted by DOE-SC. The results of DOE-SC's validation were delivered by PNSO in a PNSO-issued report (see Appendix B, "Client Validation of Work Conducted at the Pacific Northwest National Laboratory"). 


\subsection{Assumptions}

In order to develop the PNNL Site Plan, assumptions had to be made and agreed to by the PNNL project team. Those assumptions are listed below.

- The quantification of the facilities space need by type of space (gap) and projection of future program funding by client (forecast) is as presented to DOE on January 29, 2013.

- A line item project is proposed, funded by the SLI program (initially $\angle \$ 100 \mathrm{M}$, later revised to $<\$ 50 \mathrm{M})$, with a projected authorization date of 2019. Space provided by the line item project will not be available until 2022 at the earliest.

- Third party financed facilities on privately owned land are a viable solution to meet specific space needs, as long as they remain below the \$50M Office of Management and Budget (OMB) approval threshold (sum of lease payments with initial Tenant Improvements over term).

- IGPPs are a viable solution to meet specific space needs constrained by a $\$ 9.5 \mathrm{M}$ total estimated cost (TEC) and will be located on federal land.

- Parametric cost estimating methods using past PNNL actual construction cost data will be the basis for determining scenario total project costs.

- Life cycle costs will be included for all scenarios.

- The approved FY 2013-2017 Facilities and Infrastructure Investment Plan is the current facilities strategy for PNNL.

- The PNNL Campus Master Plan dated September 2012 is the current and approved plan.

- The 10-year planning horizon for implementing the strategy is FY 2014-2023.

- DOE agrees with need for flex space.

- DOE/U.S. Department of Homeland Security (DHS) are the main drivers for the facility needs.

- Existing third party lease agreements remain intact for current lease term.

- RTL will be vacated by 2020 and remediated by 2022 (consideration will be given to accelerating this date).

- 300 Area facilities are retained until PNNL no longer has a mission need for the facilities. 
- Funding levels:

For the first 5 years, the funding level for IGPP acquisition projects will be $\$ 12 \mathrm{M}$; for the second 5 years, the funding level will be $\$ 8 \mathrm{M}$ (per PNNL chief financial officer [CFO] direction).

- Annual Facilities \& Infrastructure budget will determine the pace of new facility acquisitions-IGPP and third party.

- Renovation to BMI facilities may be considered only to increase functionality, with payback in the window of government rights (Battelle contract plus 5 years).

- Economics over the 10-year planning horizon will drive the list of targeted facilities for strategic exits:

○ Service life of all facilities is considered viable for the study period.

○ Agreement on economics-based facility "targets of opportunity" list is needed with PNSO before the alternatives analysis study.

- 30-year study period for the Life Cycle Cost Analysis includes only the affected facilities within the proposed alternatives.

- ECONPACK software (U.S. Army Corps of Engineers [USACE]) will be used for the life cycle cost analysis.

- Investment and operations and maintenance $(\mathrm{O} \& \mathrm{M})$ costs will be differentiated by ownership, method of delivery (IGPP, third party, or SLI), and Facility Information Management System (FIMS) usage code.

- The type of facility (e.g., Office, Laboratory, Other Laboratory, Computational Laboratory, and Shops/Warehouse) and operating costs inform the facility exit strategy:

- Allocations are excluded.

- Lease costs will compare like types of facilities to provide an apples to apples comparison of facilities. 


\subsection{Additional Space Needs}

In addition to the gap analysis performed for mission-related space, space needs incorporated remediation impacts and the opportunity to optimize the campus over the next 10 years. A summary of the needs and analysis is provided below.

\subsection{Contract Requirement (Remediation Impacts)}

The current PNNL Contract (http://doeprimecontract.pnnl.gov/default.asp) requires remediation of the radiological contamination in the BMI facilities (see Section J, Appendix J, paragraph 8). The RTL complex at the south end of the campus is one of the contaminated facilities requiring remediation. Preliminary assessment information assumes that the most effective and efficient remediation will be to demolish RTL. Encroachment by the public, including the mixed use development in Innovation Center, urges expedition of the remediation plans. The core capabilities impacted by the remediation include Systems Engineering and Integration, Environmental Subsurface Science and Applied Materials Science and Engineering. The elimination of key research space due to the demolition is added to the mission alignment gap analysis.

The facilities in the contract will be remediated (except RTL) by September 30, 2017. The project assumes approximately $3 \mathrm{~K} \mathrm{ft}^{2}$ of laboratory "swing" space is required as contingency, in case restoration requires vacating lab space. These needs will be incorporated in the scenario planning. Plans for RTL (Lab $1 \& 2$ : $8 \mathrm{~K}$ net $\mathrm{ft}^{2}$, Lab 3: $12 \mathrm{~K}$ net $\mathrm{ft}^{2}$, Office: $14 \mathrm{~K}$ net $\mathrm{ft}^{2}$ ) include vacating the facility by June 2020 in support of remediation and decommissioning and demolition (D\&D); this is a prerequisite milestone. The facility is contractually required to complete the D\&D by September 30, 2022. Based on the projected needs, an opportunity exists to optimize the campus footprint and absorb some radiological and support space into the facility portfolio.

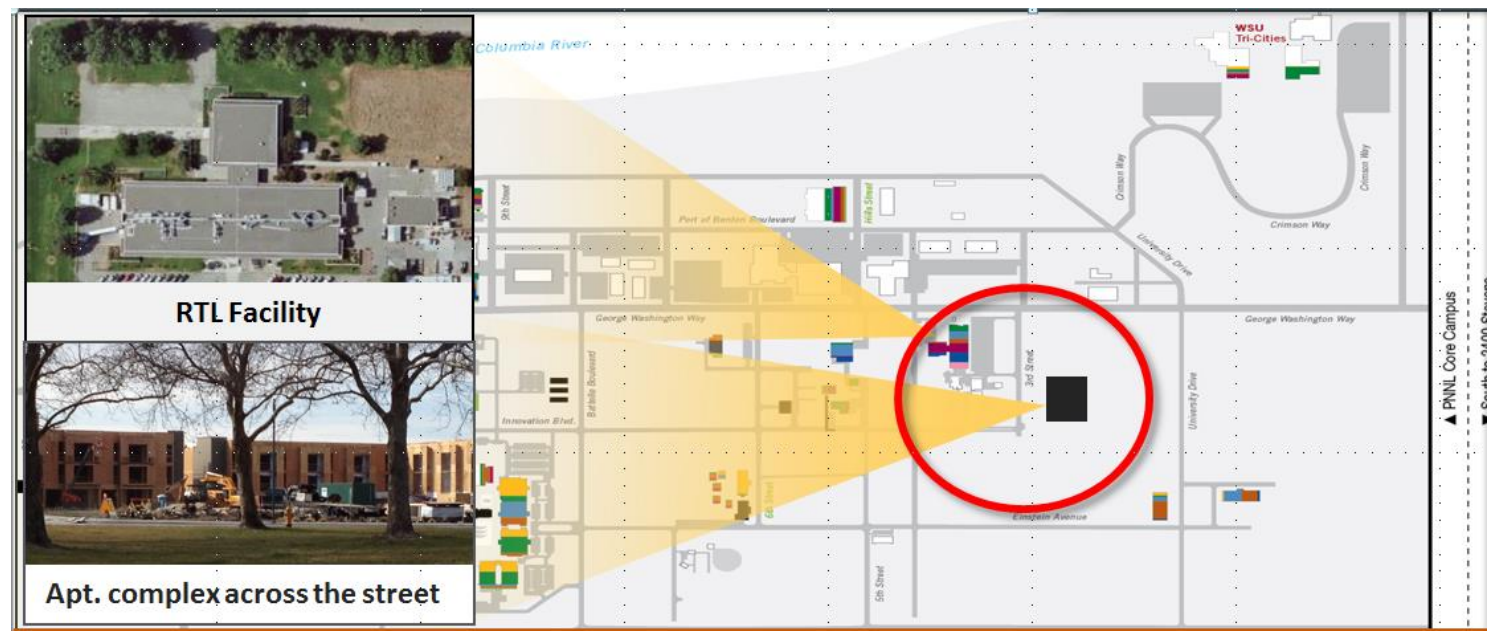

Figure 2.1. Location of RTL on PNNL Campus and the Adjacent New Apartment Complex 


\subsection{Campus Optimization}

To achieve the strategic objective of a continuous campus and optimize the campus operations, a review of older, non-federal facilities was conducted to identify those that may be less efficient. In order to determine possible candidate facilities for exit, each was categorized by its function and major space type, and the operating costs of each were analyzed.

\section{Building by Major Space Category}

Each of the PNNL Richland-campus facilities was binned into a major space category as follows: Laboratory and Laboratory-Other (special use/high bay), Office, and Shop/Warehouse. This was accomplished by reviewing the space types and quantities in each building and selecting the predominant space type and/or function, leveraging the information in PNNL's FIMS database. For subsequent analysis, buildings were compared within that major space category only. Buildings by space category are shown below.

Table 2.1. Buildings by Space Category

\begin{tabular}{|c|c|c|c|c|}
\hline \multicolumn{5}{|c|}{ Facility Category for Economic Analysis } \\
\hline $\begin{array}{c}\text { Computation } \\
\text { Laboratory }\end{array}$ & Laboratory & Other Labs & Office & Shops/Whse \\
\hline CSF & BSF & PSF 3440 & AUD & 350 \\
Salk & BSEL & 3425 & ISB1 & BRSW \\
& RPL & PDLE & ISB2 & RSW \\
& BIL & PDLW & NSB & 3475 \\
& APEL & CEL & ETB & TSW \\
& EMSL & PGF & Sigma5 & GES \\
& AML & & LSB & \\
& Sigma1 & \\
& Stevens & & Sigma2 & \\
& RTL & & Sigma3 & \\
& SSL2 & Sigma4 & \\
& RSL & SEF & \\
& 331 & Math \\
& 3410 & ESB \\
& 3420 & 3455 & \\
& 318 & 3465 \\
\hline
\end{tabular}

\section{Operating Costs}

By combining operating metrics with maintenance forecasting data, PNNL was able to analyze the tradeoffs between facility costs and mission accomplishments in support of the F\&I strategy. The operational cost metrics are based on the last 5 years of direct building operating costs. Forecast data came from the Maintenance \& Renewal Forecast System (MARS), which is a recognized industry standard for maintenance costs forecasting applications. PNNL analyzed building-to-mission comparison 
by placing the building cost metrics on a square footage basis, inclusive of both gross and net functional square feet. Reviewing the data on a square foot basis allowed the future liability of direct O\&M costs to be understood for existing and new acquisitions. This provides a standard for cost comparisons of future analysis, and the approach will be incorporated into the Facility Strategic Planning processes used to support future decisions pertaining to PNNL's facility portfolio.

\section{Cost Per Square Foot Data}

The metric of direct cost per square feet of laboratory and office space in PNNL facilities promotes effective financial trade-offs in making facility decisions. PNNL's financial processing system (FPS) consistently captures costs by common budget categories for all facilities. The Landlord system contains detailed data describing the make-up of the square footage in each building. Dividing the costs by square feet gives a common comparator across facilities. Comparing the costs for usable square feet enables a normalized decision-making approach that was standardized across all facilities. Figure 2.2, below, provides a process overview.

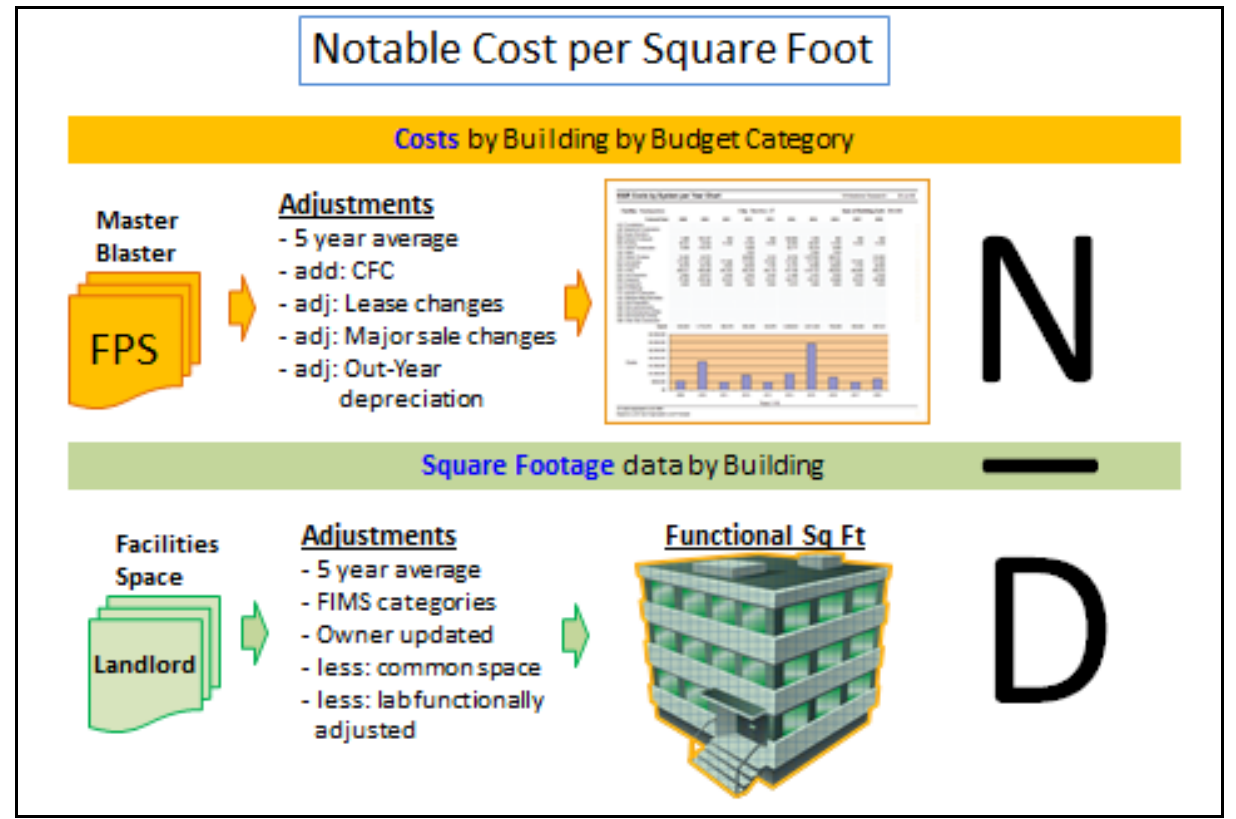

Figure 2.2. Process for Determining Notable Outcome Cost Per Square Foot

\section{Facility Costs by Budget Category}

Referencing Figure 2.2 above, "N" (the numerator) is cost. PNNL has consistently tracked costs by budget category for each facility since 2001 . While continuously improving the cost capture process, these budget categories have been consistently used over time. At the end of each fiscal year, cost data by budget category is captured in the "FY\#\# B\&U Annual Cost Rollup Data:" file and downloaded to the Operational Systems Directorate (OSD) Business Office server. 
In support of this project, five adjustments are made to this data:

1. 5-Year Average: An average cost for each budget category is calculated using the last 5 years. This is done to remove annual anomalies.

2. Add CFC Costs: The Cost of Facilities Capital (CFC) is interest cost incurred for the last completed fiscal year and reimbursed by the government. The total is captured and spread based upon current year facility depreciation in BMI facilities.

3. Lease Adjustments: Based on the lease service rate data from the Real Estate Management Office (REMO), an applicable budget category data is created.

4. Major Sales Adjustment: Based on REMO-forecasted sales of PNNL space to external entities, an applicable budget category data is adjusted for space sales.

5. Out-Year Depreciation: Based on Property Accounting balances for each facility and work in progress, out-year depreciation balances are appropriately adjusted.

The result provides a comparable future estimate of costs by budget category for each PNNL facility.

\section{Square Footage of Usable Space}

In Figure 2.2 above, "D" or the denominator is usable square footage. PNNL tracks space costs by billed space types: laboratory, office, storage, and common. This data is captured in PNNL's Landlord system. A database of space type is maintained for each PNNL facility.

Five modifications are made to adjust square footage:

1. 5-Year Average: An average footprint for each space type is calculated using the last 5 years. This is done to remove annual anomalies.

2. Add FIMS Categories: PNNL and DOE desired to compare "like" facilities. The FIMS categories were adopted to enable comparisons between various DOE sites.

3. Owner Update: Lease ownership categories have been reconciled with the sun setting of the Use Permit.

4. Common Space: Based on the lease service rate data from the REMO, an applicable budget category data is created. This is done to enable a comparison on useful space.

5. Laboratory Functional Adjustment: Based on an analysis of standard capabilities for wet chemistry space, PNNL evaluated the capability of all wet chemistry space. For space that was less than fully functional, a square foot adjustment was calculated. This adjustment enables a comparison of useful space.

The facility costs are divided by the functional square feet (N/D). The product is a reasoned cost comparator of the beneficial square footage in each PNNL facility. This data empowers an approach for 
economic facility comparisons, where facility cost can be clearly differentiated based on type of space and ownership. This allows for balancing economic data with other strategic objectives to make better trade-offs in determining facility options.

\section{Benefit}

This approach is a measured and repeatable approach which provides a clear understanding of the relationship between the costs and mission of each PNNL facility, thus enabling more informed decisions concerning balancing operating costs and obtaining a more productive operating environment. The data also provides increased confidence for internal and external decision makers, aids in making trade-offs between mission options, assists in balancing different space types, and improves the ability to support strategic campus planning.

\section{Future Maintenance Costs}

Maintenance cost forecasts were developed by the cognizant building engineers and building managers for each facility. Cost forecasts for preventive and corrective maintenance for each facility were primarily based on facility-specific budget and actual spending data from many years of cost collection. Cost forecasts for major planned maintenance and rehabilitation were based on facility condition assessment reports, deferred maintenance estimates, and MARS replacement task forecasts for each facility.

\section{Facility Economic Analysis Summary}

One of the four strategic objectives is Campus Continuity-increasing federal control of facility assets. To do that, older, privately owned buildings not on the core campus were analyzed for annual operating costs, anticipated future maintenance and rehabilitation costs, and space types. This information was used to rank the facilities, resulting in the order of priority for exit. The final spreadsheet reflecting that effort is included in Appendix C. 


\subsection{Total Space Gap}

The resulting total space gap, therefore, addressed the gaps identified in Phase I (multi-purpose programmatic and strategic intent), as well as the new gaps identified in Phase II (remediation and facility exit). The total gap summary is presented below.

Table 2.2. Total Space Gap

\begin{tabular}{|c|c|c|c|c|c|}
\hline \multirow{3}{*}{ Space Type } & \multicolumn{2}{|c|}{ Gap } & \multirow{2}{*}{$\begin{array}{c}\text { Surplus } \\
\text { Space } \\
\text { Exits FY } \\
\text { 2013-2014 }\end{array}$} & \multirow[t]{2}{*}{ RTL Exit } & \multirow[t]{2}{*}{$\begin{array}{c}\text { Revised } \\
\text { Gap }\end{array}$} \\
\hline & Surplus & Need & & & \\
\hline & \multicolumn{5}{|c|}{ Functional Sq. Feet (K) } \\
\hline Office & 53 & & -33 & -14 & 6 \\
\hline $\begin{array}{l}\text { Chemistry/Materials } \\
\text { Radiological }\end{array}$ & 4 & & & -2 & 2 \\
\hline $\begin{array}{l}\text { Chemistry/Materials } \\
\text { Non-Radiological }\end{array}$ & & 14 & -3 & -2 & 19 \\
\hline Biological/Procedure & 23 & & -17 & -1 & 5 \\
\hline Instrumentation & 11 & & 0 & -8 & 3 \\
\hline Lab Support & 8 & & -1 & -6 & 1 \\
\hline Computational & 2 & & -2 & 0 & 0 \\
\hline Imaging & & 5 & & 0 & 5 \\
\hline Other & 9 & & -6 & 0 & 3 \\
\hline
\end{tabular}




\subsection{Alternatives}

A set of alternatives based on the various bounding conditions was developed to address the total space gap forecasted over the next 10 years. The descriptions of each alternative are contained in this section. The sequence of facility builds and exits and the impact to both GSF and NSF for each of the alternatives are shown in the Mass Balance Table that can be found in Appendix D.

\subsection{IGPP}

The IGPP-only alternative provides 11 new facilities ranging in size from $12 \mathrm{~K}$ to $22 \mathrm{~K}$ GSF, totaling $211 \mathrm{~K}$ GSF for a 10 -year capital investment cost of $\sim \$ 100 \mathrm{M}$. This alternative enables the exit of 28 existing facilities, totaling $251 \mathrm{~K}$ GSF for a net reduction to the campus of $40 \mathrm{~K}$ GSF. This alternative reduces the average age of facilities (total campus including 300 Area) by 24 percent.

\subsection{IGPP and Third Party}

The IGPP \& Third Party Lease alternative adds a 60K GSF third party leased building to the IGPPs of the IGPP-only alternative above, providing a total of 12 new facilities and 271K GSF for a 10-year capital investment cost of approximately $\$ 100 \mathrm{M}$. It enables the exit of 29 existing facilities totaling $333 \mathrm{~K}$ GSF, for a net reduction to the campus of $62 \mathrm{~K}$ GSF. This alternative reduces the average age of facilities (total campus including 300 Area) by 24 percent.

\subsection{IGPP, Third Party, and SLI}

The IGPP, Third Party Lease \& SLI alternative add a 50K GSF line-item-funded building to the previous alternative, providing 13 new facilities totaling $328 \mathrm{~K}$ GSF, for a 10 -year capital investment cost of approximately $\$ 145 \mathrm{M}$. It enables the exit of 32 existing facilities totaling $386 \mathrm{~K}$ GSF for a net reduction to the campus of 57K GSF. This alternative reduces the average age of facilities (total campus including 300 Area) by 28 percent.

\subsection{IGPP and SLI}

The final alternative, IGPP \& SLI, also provides 13 new facilities (11 IGPPs, a line-item-funded building, and also includes the proposed Applied Process Engineering Laboratory [APEL] acquisition in FY 2013) totaling 299K GSF for a 10-year capital investment cost of approximately $\$ 145 \mathrm{M}$. This alternative enables the exit of 31 existing facilities totaling $366 \mathrm{~K} \mathrm{GSF}$, for a net reduction of the campus by $66 \mathrm{~K}$ GSF. This alternative reduces the average age of facilities (total campus including 300 Area) by 27 percent. 


\subsection{Evaluation of Alternatives}

\subsection{Overview}

Originally, the alternatives analysis was planned to take the form of a traditional approach, with the format following DOE O 413.3b principles. However, as the project progressed, PNSO and PNNL made a decision to use a more qualitative approach, measuring against the strategic objectives in conjunction with a comparison of key quantitative metrics among the alternatives.

This section provides information on the metrics used to evaluate the alternatives and the results of that evaluation.

\subsection{Metrics Analyzed}

In performing the alternative analysis, qualitative metrics were vetted and established through an iterative process to ensure alignment with the overarching DOE-SC guidance to meet the strategic objectives of the FY 2013 Notable Phase II study for identifying the preferred alternative. The qualitative metrics include:

- Mission Alignment - the ability to maintain customer satisfaction

- Campus Continuity - increasing the federal control of assets on the PNNL campus

- Reasonable \& Achievable - do what makes sense from a practical and cost perspective

- Campus Master Plan - ensure a mission ready, modern, collaborative, flexible, and sustainable campus.

In support of the qualitative analysis, quantitative metrics were established to provide an objective analysis. These include:

- Schedule for filling the mission gap (wet chemistry, imaging, remediation)

- GSF of non-federal buildings exited

- Percent federal ownership of PNNL facilities

- Percent federally owned wet chemistry laboratory space

- Impact to the annual, direct O\&M costs

- Life Cycle Cost Analysis. 
Additional metrics analyzed for each alternative included:

- Total GSF Lab footprint change

- Net Present Value per GSF of new construction

- Change in operating costs

- Change in the number of buildings (federal and non-federal)

- Percent change in campus ownership (federal, BMI, lease)

- 10 -year change in space type by square feet:

- Biological/procedure

○ Instrumentation

○ Other

○ Lab support

○ Chemistry - radiological

- Computational

○ Imaging

○ Chemistry - non-radiological.

The Life Cycle Cost Analysis results with GSF changes are summarized in Table 4.1 below. 
Table 4.1. Life Cycle Cost Analysis Summary

\begin{tabular}{|c|c|c|c|c|c|}
\hline \multicolumn{6}{|c|}{ Life Cycle Cost Analysis Summary } \\
\hline & \multicolumn{2}{|c|}{$\begin{array}{c}\text { IGPP } \\
\text { Construction }\end{array}$} & $\begin{array}{l}\text { IGPP \& 3rd } \\
\text { Party Lease }\end{array}$ & $\begin{array}{l}\text { IGPP, 3rd Party } \\
\text { Lease \& SLI }\end{array}$ & IGPP \& SLI \\
\hline 10-Year Inves tment Cost & & $100,000,000$ & $\$ 100,000,000$ & $\$ 145,000,000$ & $\$ 145,000,000$ \\
\hline Net Present Value & & $101,886,840$ & $\$ 138,036,351$ & $\$ 181,431,737$ & $\$ 124,065,350$ \\
\hline NPV/GSF Built* & $\$$ & 483 & $\$ \quad 510$ & $\$ \quad 553$ & $\$ \quad 458$ \\
\hline \multicolumn{2}{|l|}{ GSF Built* } & 210,800 & 270,800 & 328,300 & 299,300 \\
\hline \multicolumn{2}{|l|}{ GSF Vacated** } & $(250,884)$ & $(333,040)$ & $(385,735)$ & $(365,735)$ \\
\hline \multicolumn{2}{|l|}{ GSF Impact to Campus } & $(40,084)$ & $(62,240)$ & $(57,435)$ & $(66,435)$ \\
\hline \multicolumn{6}{|l|}{ Future Operational Cost Changes } \\
\hline FY13 Direct O\&M Budget & $\$$ & $64,664,059$ & $64,664,059$ & $64,664,059$ & $\$ 64,664,059$ \\
\hline Total FY13/14 Planned Exits & $\$$ & $(2,724,362)$ & $(2,724,362)$ & $(2,724,362)$ & $\$ \quad(2,724,362)$ \\
\hline Total New Campus Facilities & $\$$ & $2,790,182$ & $5,567,141$ & $6,434,866$ & $3,699,332$ \\
\hline Total Outyear Planned Exits & $\$$ & $(3,257,364)$ & $(5,069,818)$ & $(6,109,418)$ & $\$ \quad(5,654,418)$ \\
\hline \multirow{2}{*}{$\begin{array}{ll} & \text { Totals } \\
\end{array}$} & $\$$ & $61,472,515$ & $\$ 62,437,020$ & $62,265,145$ & $\$ 59,984,611$ \\
\hline & 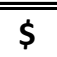 & $(3,191,544)$ & $(2,227,039)$ & $(2,398,914)$ & $\begin{array}{l} \\
\$(4,679,448)\end{array}$ \\
\hline $\begin{array}{l}\text { O\&M Annual Delta } \\
\text { O\&M \% Decrease }\end{array}$ & & $-5 \%$ & $-3 \%$ & $-4 \%$ & $-7 \%$ \\
\hline \multicolumn{6}{|c|}{$\begin{array}{ll}* & \text { NPV/GSF Built based on actions occuring within the study period, FY14-23 } \\
* * & \text { GSF Built for IGPP \& SLI includes the GSF added by the planned APEL acquisition in FY13 } \\
* * * & \text { Inclusive of FY13/14 Actions Underway (Sigma } 3 \& 5 ; \text { BIL; PGF; LSL II ***) } \\
* * * * & \text { LSL-II is not being exited but is associated with those facilities listed }\end{array}$} \\
\hline
\end{tabular}

\subsection{Analysis}

Alternative 1 - IGPP Only: delivers the wet chemistry need in FY 2019, the imaging need in FY 2020, and enables the exit of RTL in FY 2019. This alternative provides 11 new facilities totaling $211 \mathrm{~K}$ GSF, for a 10 -year capital investment cost of $\$ 100 \mathrm{M}$, and enables the exit of 28 existing facilities totaling $251 \mathrm{~K}$ GSF for a net reduction to the campus of 40K GSF, while increasing federal ownership of the campus by 10 percent. Inclusive of all costs, the net present value (NPV) of this alternative is $\$ 102 \mathrm{M}$, yielding an NPV/GSF built value of $\$ 483 / \mathrm{GSF}$. When all actions within the alternative are complete, a savings of $\$ 3 \mathrm{M}$ (5 percent) annual direct O\&M are realized.

Strengths:

- Low initial capital investment

- High level of local control surrounding investments 
Weaknesses:

- Delivers the wet chemistry gap the latest

- Dispersed research collaboration and capabilities

- Small incremental additions; lacks an additional anchor facility

Resulting Metrics:

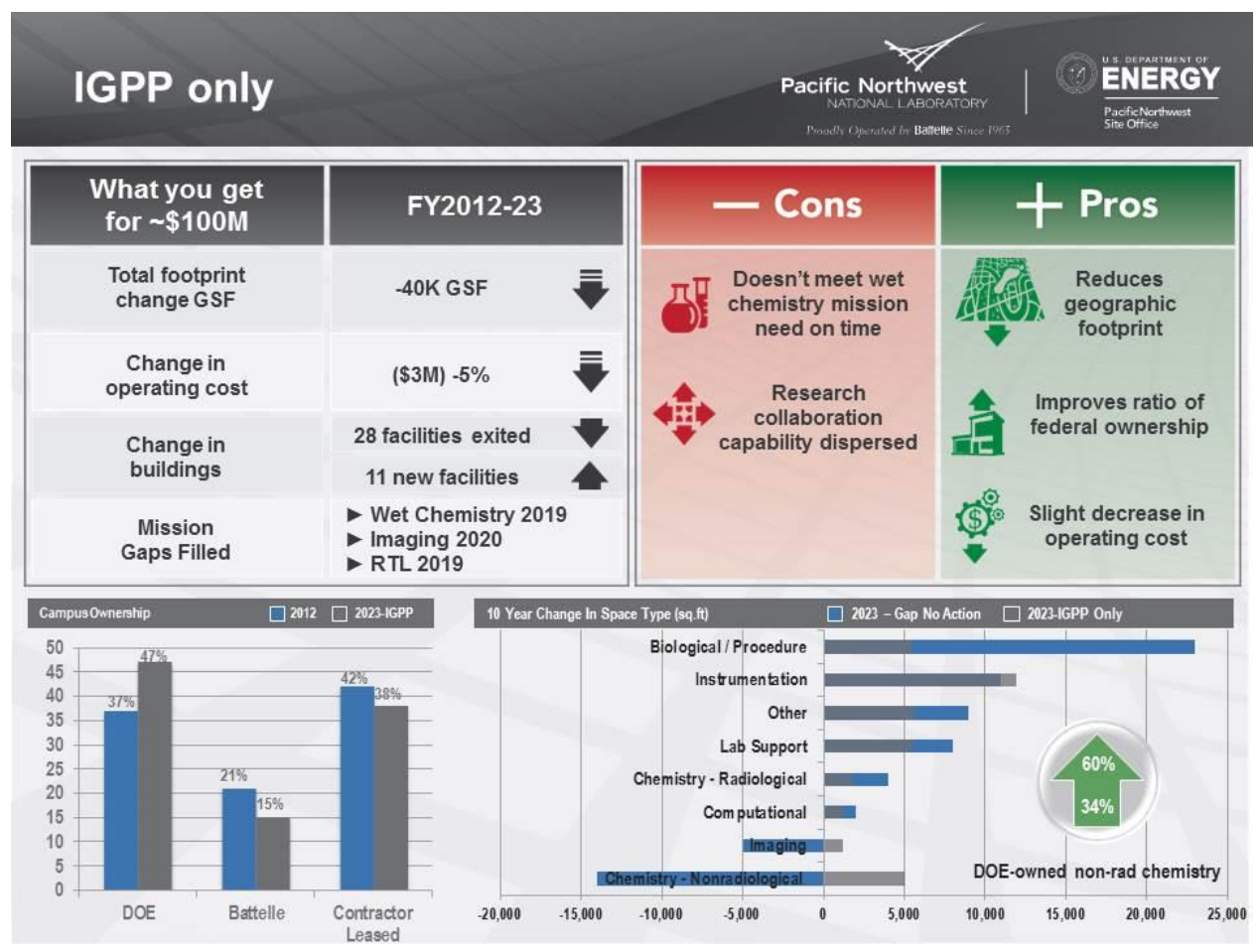

Figure 4.1. IGPP Metrics

Alternative 2 - IGPP \& Third Party Lease: delivers the wet chemistry need in FY 2017, the imaging need in FY 2020, and enables the exit of RTL in FY 2018. This alternative provides 12 new facilities totaling $271 \mathrm{~K}$ GSF, for a 10 -year capital investment cost of $\$ 100 \mathrm{M}$, and enables the exit of 28 existing facilities totaling $333 \mathrm{~K}$ GSF for a net reduction to the campus of $62 \mathrm{~K}$ GSF, while increasing federal ownership of the campus by 11 percent. Inclusive of all costs, the NPV of this alternative is $\$ 138 \mathrm{M}$, yielding an NPV/GSF built value of $\$ 510 / \mathrm{GSF}$. When all actions within the alternative are complete, a savings of $\$ 2 \mathrm{M}$ (3 percent) annual direct O\&M are realized.

Strengths:

- Accelerates critical wet chemistry mission delivery

- Accelerates RTL exit and succeeding decontamination and demolition activity 
- Improves research collaboration and capability co-location

- Low initial capital investment while enabling an anchor facility

Weaknesses:

- Risk associated with finding a willing developer

- Long-term annual lease liability with ownership potentially reverting back to land owner

Resulting Metrics:

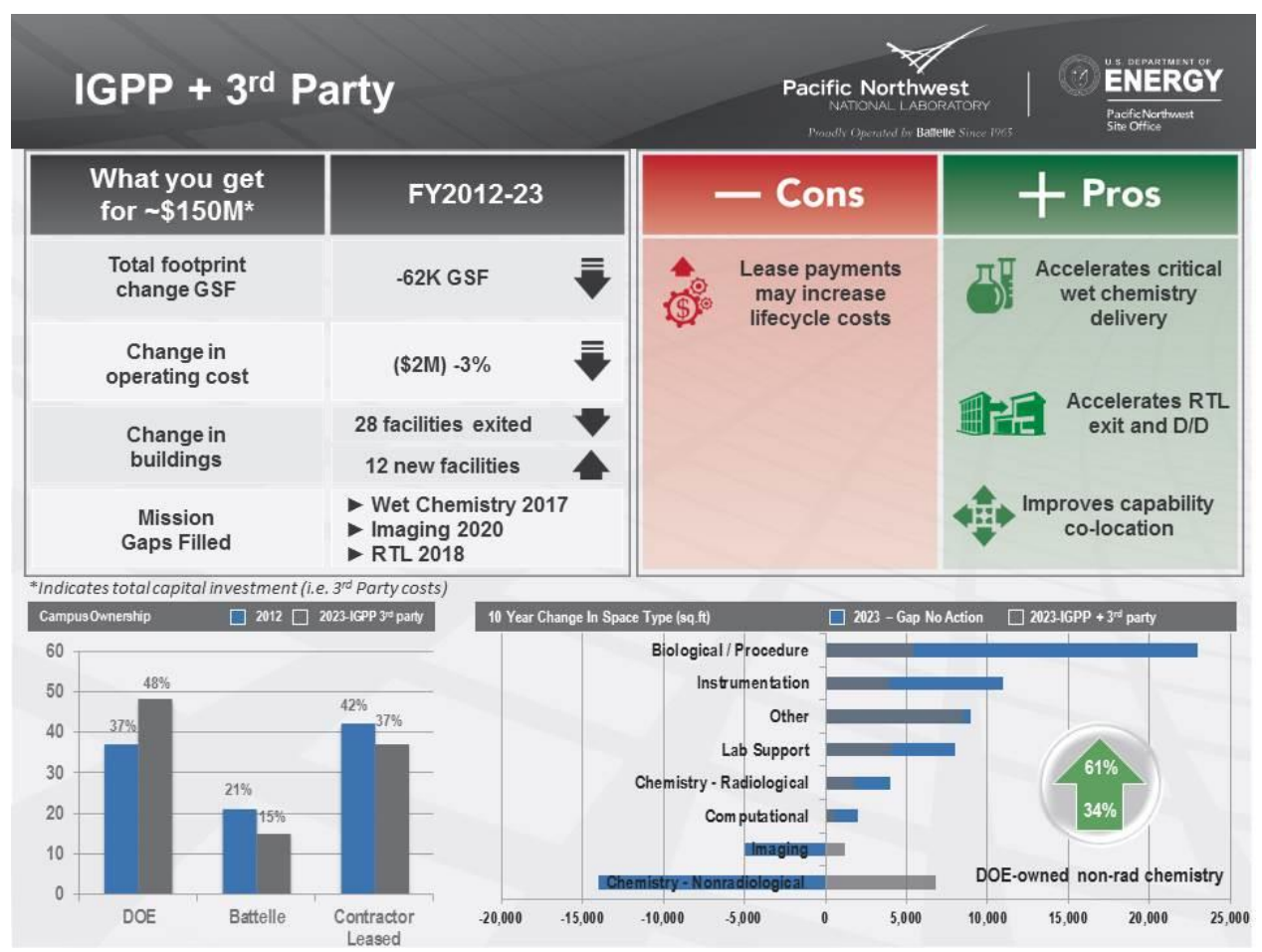

Figure 4.2. IGPP and Third Party Metrics

Alternative 3 - IGPP, Third Party Lease \& SLI: delivers the wet chemistry need in FY 2017, the imaging need in FY 2020, and enables the exit of RTL in FY 2018. This alternative provides 13 new facilities totaling $328 \mathrm{~K} \mathrm{GSF}$, for a 10-year capital investment cost of $\$ 145 \mathrm{M}$, and enables the exit of 31 existing facilities totaling $386 \mathrm{~K}$ GSF, for a net reduction to the campus of $57 \mathrm{~K} \mathrm{GSF}$, while increasing federal ownership of the campus by 13 percent. Inclusive of all costs, the NPV of this alternative is $\$ 181 \mathrm{M}$, yielding an NPV/GSF built value of $\$ 553 / \mathrm{GSF}$. When all actions within the alternative are complete, a savings of $\$ 2 \mathrm{M}$ (4 percent) annual direct O\&M are realized. 
Strengths:

- Accelerates critical wet chemistry delivery

- Accelerates RTL exit and succeeding decontamination and demolition activity

- Improves co-location of all capabilities and associated staff

- Greatest opportunity to positively impact future research and development (R\&D) mission

- Enables an additional anchor facility on the Core Campus

Weaknesses:

- Introduces risk associated with finding a willing developer

- Long-term annual lease liability

- Introduces risk associated with obtaining SLI funding

Resulting Metrics:

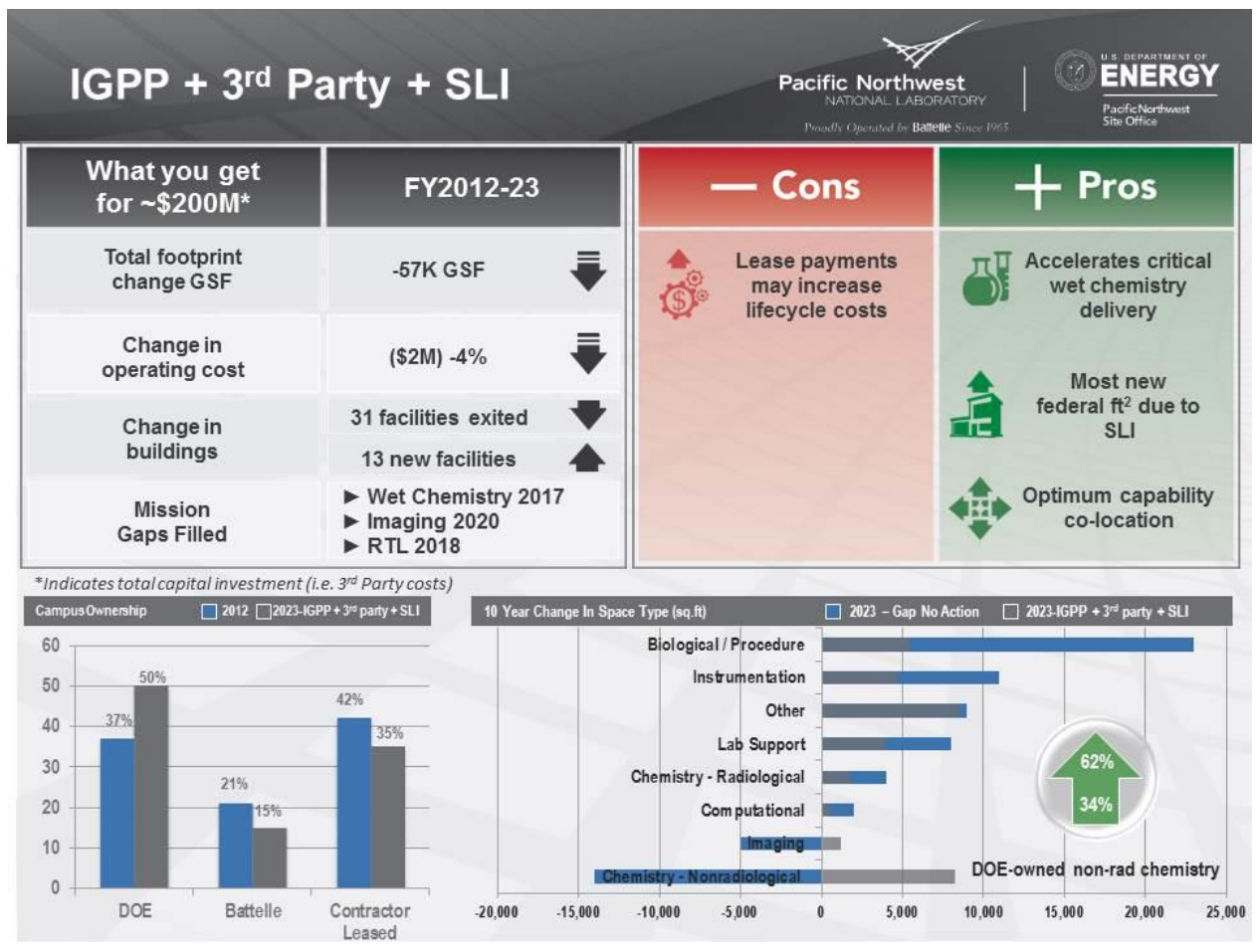

Figure 4.3. IGPP, Third Party, and SLI Metrics

Alternative 4 - IGPP \& SLI: delivers the wet chemistry need in FY 2019, the imaging need in FY 2017, and enables the exit of RTL in FY 2020. This alternative provides 13 new facilities (including the planned APEL acquisition in FY 2013) totaling 299K GSF, for a 10-year capital investment cost of 
$\$ 145 \mathrm{M}$, and enables the exit of 31 existing facilities totaling 366K GSF, for a net reduction of the campus by $66 \mathrm{~K}$ GSF, while increasing federal ownership of the campus by 15 percent. Inclusive of all costs, the NPV of this alternative is $\$ 124 \mathrm{M}$, yielding an NPV/GSF built value of $\$ 458 / G S F$. When all actions within the alternative are complete, a savings of $\$ 5 \mathrm{M}$ (7 percent) annual direct O\&M are realized.

Strengths:

- Accelerates critical wet chemistry delivery

- Improves research collaboration and capability co-location

- Adds most new federal footprint

- Provides the greatest geographical footprint reduction

- Lowest NPV/GSF built

- Greatest reduction of annual, direct O\&M costs

- Enables an additional anchor facility

- Annexing to existing federal facilities provides efficiency and flexibility

Weakness:

- Introduces risk associated with obtaining SLI funding

- Managing segmentation risk associated with IGPP funds 
Resulting metrics:

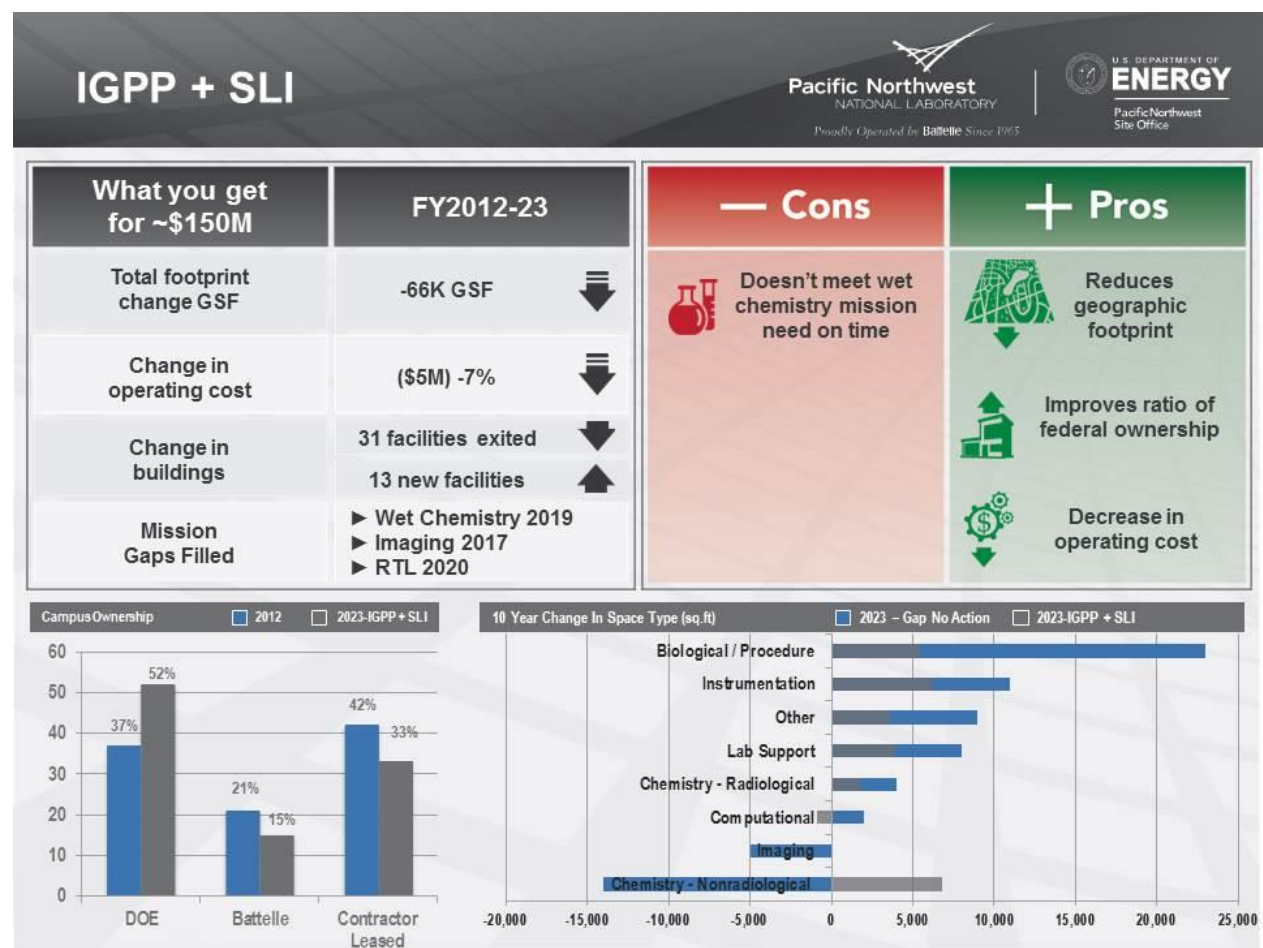

Figure 4.4. IGPP and SLI Metrics

\subsection{Evaluation of Alternatives}

A dashboard was created, combining both the qualitative and quantitative metrics, along with narrative pertaining to mission impact and other key points to determine the preferred alternative. Qualitative metrics were provided a value of excellent, very good, good, fair, or poor, while quantitative metrics returned the impacts as revealed through objective analysis. 
Table 4.2. Alternatives Analysis Findings

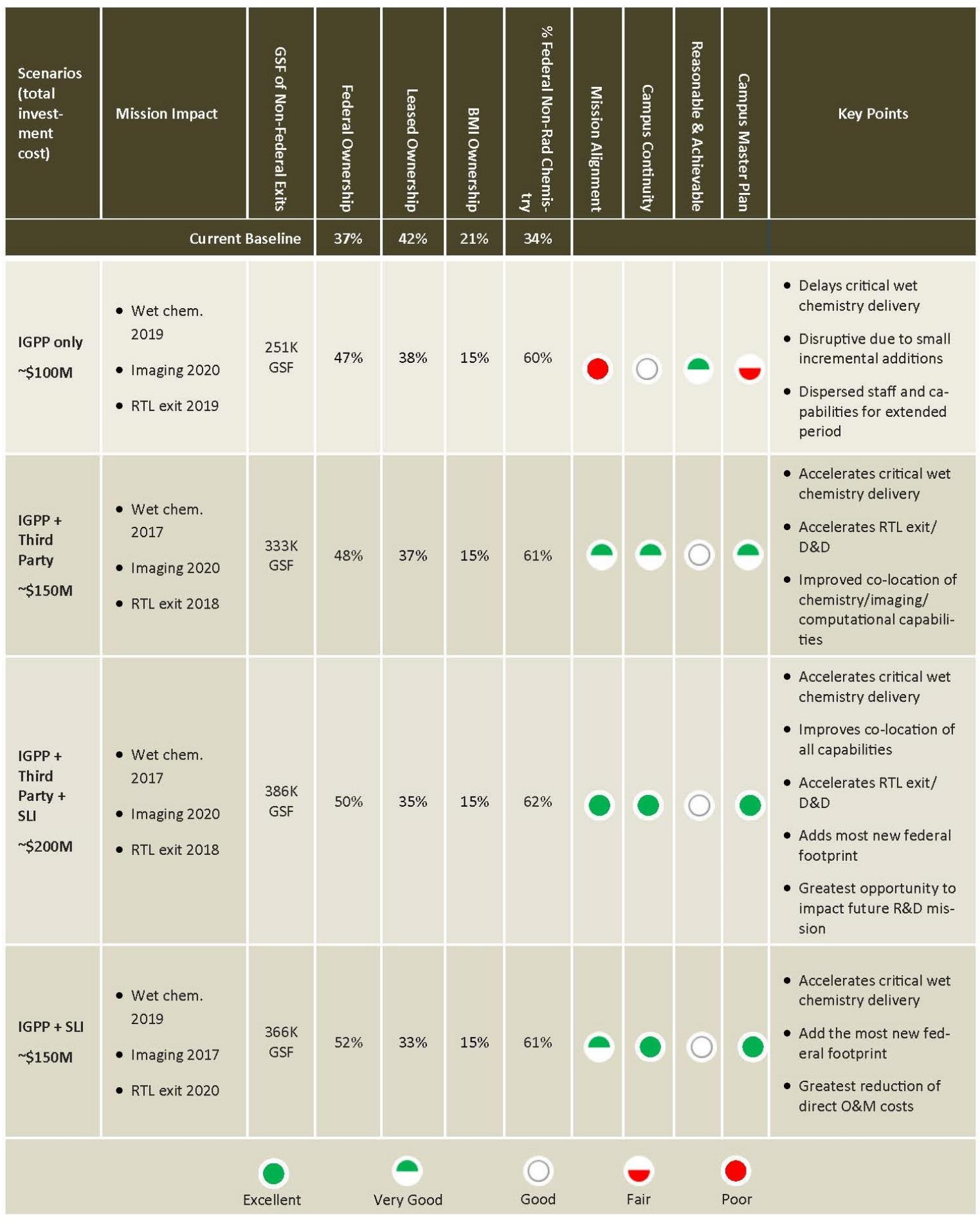




\subsection{Recommended Alternative}

\subsection{DOE Recommendation/Feedback}

The IGPP, Third Party, and SLI investment option was recommended as the preferred alternative due to meeting the objectives in the shortest amount of time. However, DOE provided additional guidance at the conclusion of the April 9, 2013 presentation, which is summarized below.

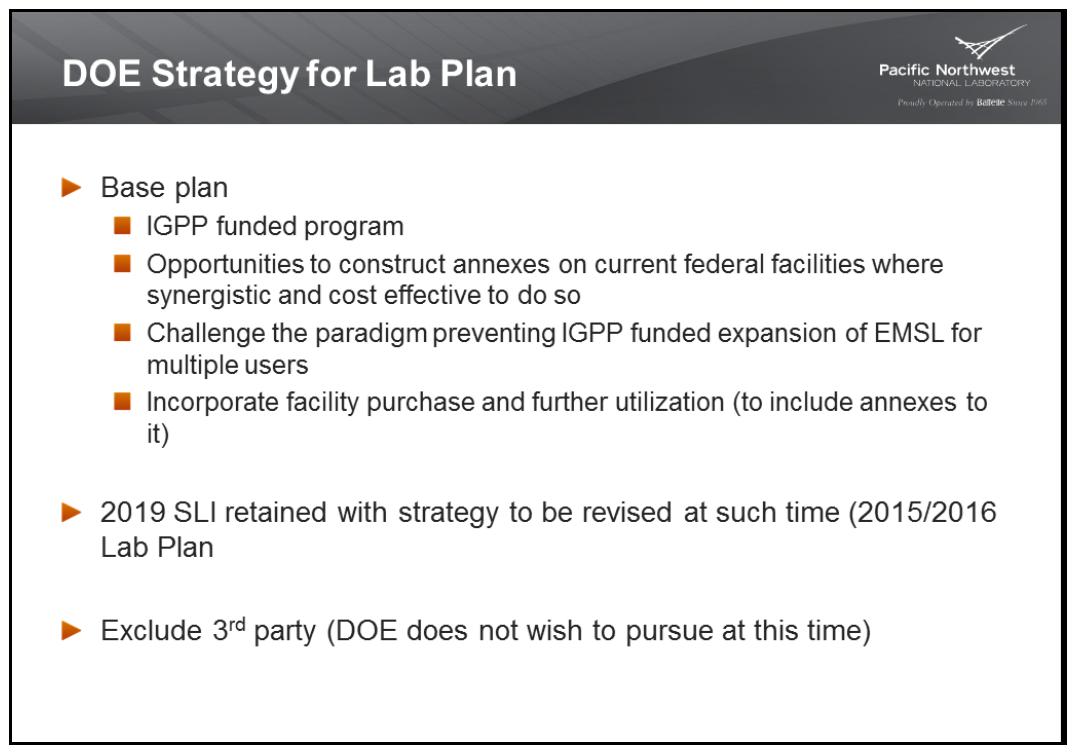

Figure 5.1. DOE Strategy for Lab Plan

\subsection{Recommended Alternative}

Based on DOE's guidance, the final recommended alternative is Alternative \#4, with adjustments noted in Figure 5.1, which uses IGPP and SLI funding to address the strategic objectives of the F\&I strategy - to keep core capabilities mission ready, deliver space and facilities according to the guiding principles, and support the achievement of PNNL's vision (i.e., to inspire and enable the delivery of world-leading S\&T in support of Laboratory missions). By implementing the recommended alternative within 10 years, PNNL's F\&I strategy will result in a mission ready PNNL campus that has decreased operating costs, decreased campus footprint, and a reduced average age of facilities, while increasing federal control of assets. Overall, this strategy results in 13 new DOE facilities and divests of 31 contractor-owned or -leased (or non-DOE) facilities.

The gap analysis, described in the previous sections, identifies needs and surplus space that will be addressed by this F\&I strategy. Where possible, the plan leverages existing space and uses capabilities already present on the campus. The F\&I strategy incorporates options to resolve the gap and maintain the campus capabilities. It includes options to transfer ownership of leased facilities to DOE, build additions/annex(es) to existing federal facilities, build stand-alone facilities (through IGPP), and to make investments to maintain existing facility and infrastructure assets. 
As one of the initial investments, DOE is investigating the acquisition of a 90,000 GSF facility with approximately 60 occupants, currently leased in part by PNNL. This facility includes wet chemistry, instrument, high bay, and office space. Non-PNNL tenants currently occupy approximately 50 percent of the facility. As these tenants vacate the facility, additional instrument and high bay space would become available to DOE/PNNL. There is also potential for future building annex(es), which could add additional high bay and large instrument scale-up space to the PNNL building as the need arises. The potential facility purchase is anticipated to be accomplished with FY 2013 IGPP funding.

Another element of the strategy addresses a space gap by acquiring new multipurpose space as annex(es) to existing federal facilities. Planned acquisitions include expansion of EMSL or other federal facilities, providing wet chemistry, imaging (quiet space), and office space. This approach may provide greater connectivity with existing research compared to building new, stand-alone buildings. Annexes to existing federal facilities will be accomplished with IGPP funds and considered when it is cost effective and the work is synergistic.

Facility annexes will partially close the mission need gap. New stand-alone IGPP facility acquisitions, located on federal land, will also be required to completely close the gap. One of the new planned IGPP acquisitions will provide multipurpose space capability, allowing, amongst other functions, the integration of modeling, monitoring, and analysis of the U.S. electric grid, supporting a broader spectrum of energy and national security research and operation in ways not possible today. This space will also house the PNNL Building Operations Control Center to centralize campus energy management and utility operations and provide a central location for managing unplanned events or emergencies affecting the campus operations. The SLI project will be designed to deliver significant impact on S\&T and support the development of a modern, synergistic core campus where a collaborative and innovative environment is fostered. The specific scientific impact will be further defined in the 2015 and 2016 Annual Laboratory Plans.

The final element of the strategy incorporates a divestment of surplus space and non-DOE facilities identified as costly or inefficient as part of the optimization analysis. In total, the strategy exits 31 leased and contractor-owned facilities outside the core campus and modernizes the campus, while eliminating the high operating costs of older facilities. 


\subsection{Summary}

In summary, the Notable Outcome Phase II project provided the background and data necessary for a facility strategy to be developed for the next 10 years. As a recap, the project's deliverables and their final status are summarized below:

- Document the data streams and process used to deliver the information for Phase I, including a plan to institutionalize the process into the space management scope of work. This work is continuing as part of the Facility Strategic Planning Office's scope of work.

- Develop scenarios with the ability to meet the identified space gap via the available funding mechanisms, through a combination of existing and new facility additions (i.e., new construction, renovation of existing space [either Battelle-owned facilities or DOE-owned facilities], additions to or renovation of existing third party leased facilities, and/or newly leased third party facilities). The scenarios will generally be characterized by scope ( $\mathrm{ft}^{2}$ by space type) initial cost, life cycle cost, and acquisition schedule. Alternatives were developed for IGPP, IGPP + Third Party, IGPP + Third Party + SLI, and IGPP + SLI funding scenarios.

- Perform an analysis of those scenarios in accordance with the consensus criteria. An alternative analysis was completed, with the recommendation of an IGPP + SLI strategy as the alternative most closely meeting the strategic objectives.

- Provide a written report documenting the work (this document).

- Deliver a PowerPoint presentation (about 20 slides) summarizing the project, process, and outcomes. A presentation was completed and delivered on April 9, 2013 by PNSO to DOE$S C$.

- Provide input to the 2014 Lab Plan, section 6.0, "Infrastructure/Mission Readiness." Based on the efforts completed in both Phase I and Phase II, input to the 2014 Lab Plan was provided and incorporated into the Laboratory planning strategy. 



\section{Appendix A}

\section{Client Validation Profile Sheets}


Appendix A

Client Validation Profile Sheets

\section{DOE SC Client Validation}

with the Office of Science 


\section{Why we are talking with you}

Informed perspective on the appropriate long term government need for the type of work performed at PNNL

- Talking to clients that compose $75 \%$ of the PNNL business

- Share data with you on how work is integrated into PNNL

- Perspective on your need for the type of work performed at PNNL

- Information will be used to:

- Validate the Contractor's $10 \mathrm{yr}$ forecast

- Understand changing needs for space/facilities

- Develop a robust, long-term strategic facilities plan for PNNL

\begin{tabular}{|l|l|}
\hline \multicolumn{1}{|c|}{ Client } & \multicolumn{1}{c|}{ Contact } \\
\hline $\begin{array}{l}\text { Science } \\
\text { BER } \\
\text { BES }\end{array}$ & $\begin{array}{l}\text { Sharlene Weatherwax } \\
\text { Harriet Kung } \\
\text { Barbara Helland }\end{array}$ \\
\hline $\begin{array}{l}\text { NNSA } \\
\text { DNN/NA-22 }\end{array}$ & $\begin{array}{l}\text { Anne Harrington and } \\
\text { Rhys Williams }\end{array}$ \\
\hline $\begin{array}{l}\text { EERE } \\
\text { DHS } \\
\text { S } \& \text { Steve Chalk }\end{array}$ & Dan Gerstein \\
\hline $\begin{array}{l}\text { SP } \\
\text { DOE IN }\end{array}$ & Steve Black \\
\hline DOE-EM & Alice Williams \\
\hline
\end{tabular}




\section{SC Profile}

SC Core Capability footprint $(\%)$

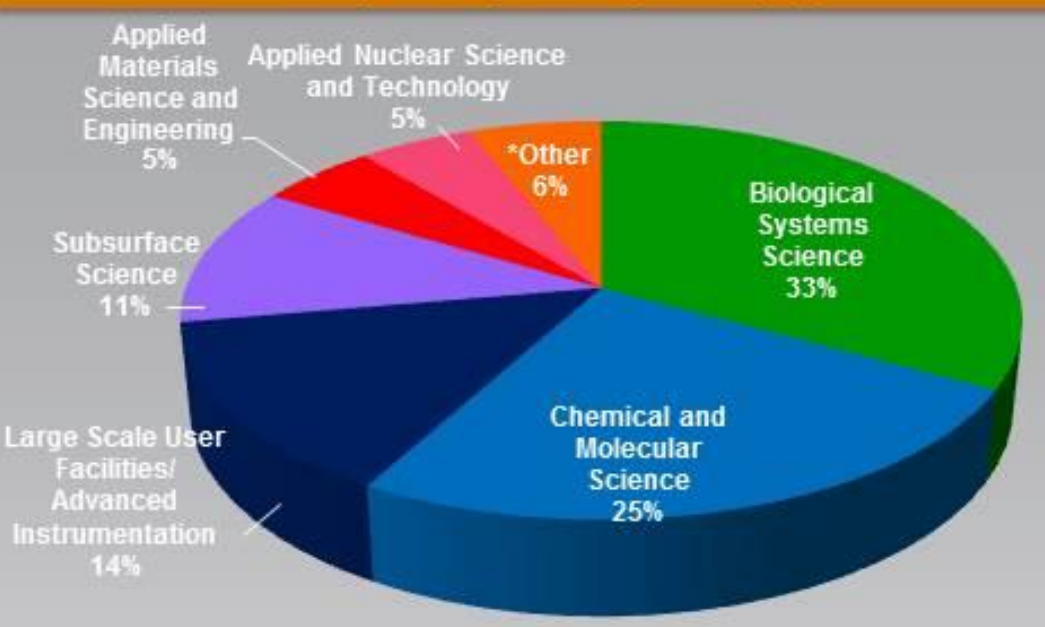

*Other includes:

Chemical Engineering - Systems Engineering and Integration

- Climate Change - Advanced Computer Science, Visualization and Data

\begin{tabular}{|c|c|c|}
\hline $\begin{array}{c}\text { Type of Space } \\
\text { Chemistry/ }\end{array}$ & SC Total Net ft ${ }^{2}$ & $\begin{array}{c}\text { \% Total Net } \\
\text { Lab-wide }\end{array}$ \\
\hline Materials & 16,884 & $23 \%$ \\
\hline Lab Support & 21,945 & $31 \%$ \\
\hline Instrument & 42,057 & $27 \%$ \\
\hline Biological/Procedure & 19,005 & $19 \%$ \\
\hline Computation & 14,961 & $20 \%$ \\
\hline Other & 12.933 & $20 \%$ \\
\hline Grand Total & $127,784^{*}$ & $\mathbf{2 5 \%}$ \\
\hline
\end{tabular}

* does not include office
SC FY2012 Funding (Cost data - \$172M)

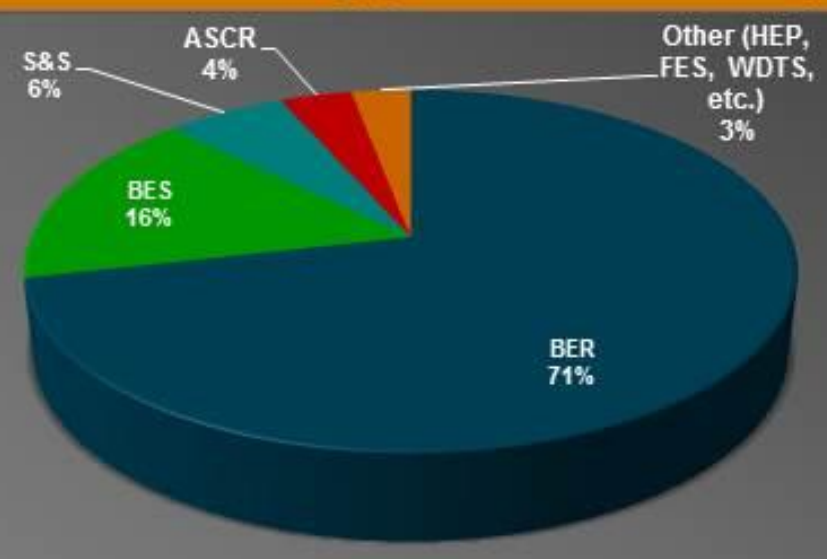

- $20 \%$ of PNNL's total FY12 funding (cost data)

\section{DOE SC Ten Year Forecast}

- Overall flat projections

- BER potential increase in biology, climate and environmental science

- BES potential increase in catalysis and materials science

- ASCR increases in data analytics, multifaceted math and exascale computing 


\section{SC Profile}

Integration of staff, facilities, and capabilities to achieve program objectives
Pacific Northwest

$$
\text { NATONAL LABORATOR }
$$

roodts opercoted by Banelle
ENERGY

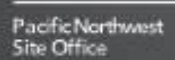

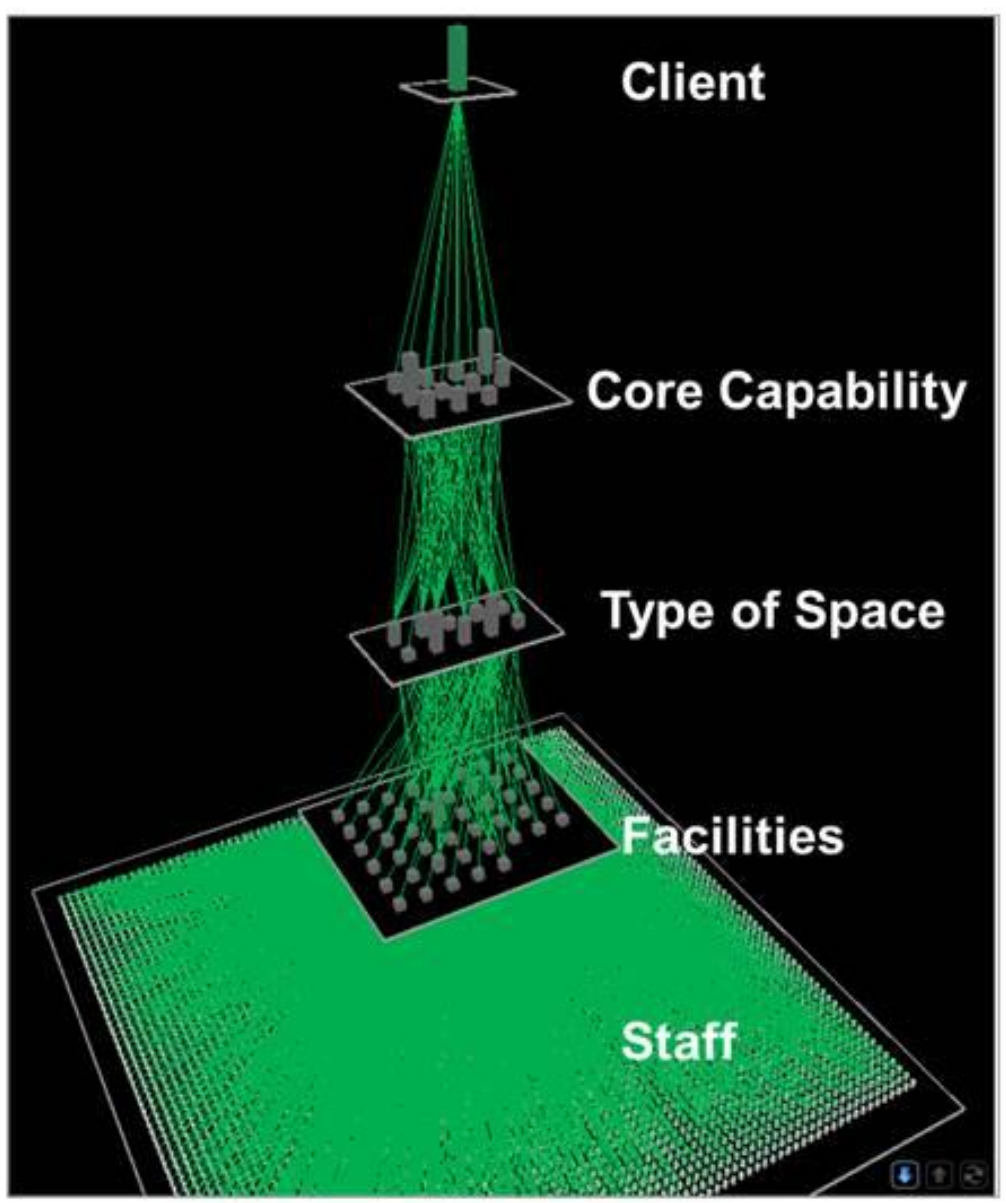

\begin{tabular}{|c|c|c|}
\hline Clients & *Direct FTEs & Staff Engaged \\
\hline DOE-SC & 534 & 1,950 \\
\hline $\begin{array}{c}\text { NNSA } \\
\text { DSP } \\
\text { (DOD, SP, IN, etc.) }\end{array}$ & 449 & 1,685 \\
\hline $\begin{array}{c}\text { DOE Energy } \\
\text { (EERE, OE, Fossil } \\
\text { Energy, etc.) }\end{array}$ & 403 & 3,035 \\
\hline DHS & 176 & 1,751 \\
\hline $\begin{array}{c}\text { DOE Other } \\
\text { DOE-EM }\end{array}$ & 127 & 1,749 \\
\hline DHHS & 83 & 870 \\
\hline NRC & 49 & 421 \\
\hline DOE-NE & 47 & 640 \\
\hline *Indirect FTEs not included & 4 \\
\hline
\end{tabular}




\section{What we would like to know}

Informed perspective on the appropriate long term government need for the type of work performed at PNNL

- In your mission area, for what specific needs/capabilities do you go to PNNL?

- For each of the areas noted above, why do you go to PNNL? (Choose as many as apply)

- World leading/competitive award

- Unique capability

- Synergy with other capabilities/programs

- Staff, equipment and/or facilities?

- Industry/market knowledge, emphasis on commercialization

- Long standing relationships

- Projectmanagement/responsiveness

- Goodvalue/low cost

How central to your mission is the work performed for you by PNNL?

- As you look out over the next 5 years, do you anticipate your funding at PNNL to increase, stay flat or decrease? Why? 


\section{Appendix B}

\section{Client Validation of Work Conducted at the Pacific Northwest National Laboratory (DRAFT)}




\section{Appendix B}

\section{Client Validation of Work Conducted at the Pacific Northwest National Laboratory (DRAFT) \\ Department of Energy \\ Office of Science \\ Pacific Northwest Site Office}

April 2013 


\section{Contents}

Executive Summary

1.0 Validation Approach

2.0 Contractor Forecast and Type of Space Needs

3.0 Validation Results

4.0 Conclusion

\section{Appendix}

A Interview Schedule

B Client Profile Presentations

C Interview Form

D Client Input Forms (Questions 1-3)

E Client Input Forms (Question 4) - Not for further distribution?

F Space Type Definitions

G Consolidated Client Input for Question 1

H Consolidated Client Input for Question 2

I Consolidated Client Input for Question 3

J Consolidated Client Input for Question 4 


\section{Executive Summary}

The Office of Science is developing a robust, long-term (10-year) strategic facilities plan for the Pacific Northwest National Laboratory. This plan will put special emphasis on clarifying the facilities situation at the laboratory and the future needs (or not) for these facilities. It will be informed by clients that utilize the laboratory and their perspectives on the long term government need for the type of work performed at PNNL. To obtain this perspective, the Office of Science and the Pacific Northwest Site Office worked together to conducted a set of interviews with clients that compose approximately 75 percent of the Laboratories business.

This report documents the approach and results of DOE's efforts to validate major customers of the laboratory and their needs and expectations of the work performed at the laboratory over the next ten years. Input received from PNNL clients validated the PNNL Contractor's forecast of relatively stable funding over the next 5-10 years. All clients interviewed provided information on the types of capabilities they will continue to need/seek from PNNL; they discussed how these capabilities are central to their mission objectives and indicated that in part, they conduct work at PNNL because the work is world leading and/or competitively awarded; their capabilities are unique; and in some cases synergistic with other capabilities and programs.

The informed perspective received from the clients validated the Contractor's forecast and provides confidence that the type of space needed over the next ten years will remain fairly consistent with the Laboratories current space types/capabilities. This information will primarily be used to inform the development of the long-term strategic facilities plan for PNNL.

\subsection{Validation Approach}

The approach to obtain an informed perspective on the appropriate long-term government need for the type of work performed at PNNL utilized two sets of information. The first set of information was a Contractor developed forecast over a 10-year period (FY 2014-2024). The second set of information was client input on what they anticipate needing from the laboratory over the next 5-10 years. The information from the clients was used to validate the forecast developed by the Contractor and identify additional perspectives that should be considered when developing a long-term facilities strategic plan.

Eight major clients (Figure 1) that compose approximately 75 percent of the Laboratory business were interviewed by a joint SC/PNSO team. Interviews were conducted in accordance with the schedule included in Appendix A. In preparation for the interviews, a presentation package was prepared for each client (Appendix B). The presentation packages included a profile specific to each client that outlined how work is integrated at the laboratory and mapped by staff, facilities and core capabilities. The profiles also highlighted the contractor's ten year forecast and types of space used to conduct the clients work. The profile packages were shared with the client as appropriate. 


\section{PNNL Clients that compose $\sim 75 \%$ of Laboratory Business}

- Office of Science Biological and Environmental Research

- Office of Science Basic Energy Sciences

- Office of Science Advanced Scientific Computing Research

- National Nuclear Security Administration

- Energy Efficiency and Renewable Energy

- Department of Homeland Security

- Office of Environmental Management

- Other

Figure 1: PNNL Clients that Compose $~ 75 \%$ of Laboratory Business

In preparation for the interviews, the following four questions were shared with the clients in advance:

1. In your mission area, for what specific needs/capabilities do you go to PNNL?

2. For each of the areas noted in Question 1, why do you go to PNNL?
a. World Leading/competitive award
b. Unique capabilities
c. Synergy with other capabilities/programs
d. Staff, equipment, or facilities
e. Industry/market knowledge, emphasis on commercialization
f. Long standing relationships
g. Project management/responsiveness
h. Good value/low cost

3. How central to your mission is the work performed for you by PNNL?

4. As you look over the next 5 years, do you anticipate your funding at PNNL to increase, stay flat, or decrease? Why? 
The question set was discussed in the interview and in most cases the clients followed up with written responses to the questions. Client responses were input by the interview team into a standard interview form (Appendix C) to allow for consolidation of the information. Forms with client input for questions 13 are contained in Appendix D and input for question 4 is contained in Appendix E. Question 4 was separated from questions 1-3 and should not be shared with the contractor per the client's request.

\subsection{Contractor Forecast and Type of Space Needs}

The PNNL Contractor's 10-year cost analysis and projections are reflected in Figure 2. Over the next 10 years, the contractor foresees relatively stable funding. This recognizes that there may be decreases in some programs which are offset by increases in others. The projection does not account for unknow impacts due to events like sequestion. The projections are a programmatic build up and reflect normal course of business discussions between the contractor and the clients. An analysis of the accuracy of the contractor's business planning projections over a five year period (FY 2007-2012) indicate that historically, their estimates have been conservative giving additional confidence in the out-year projections.

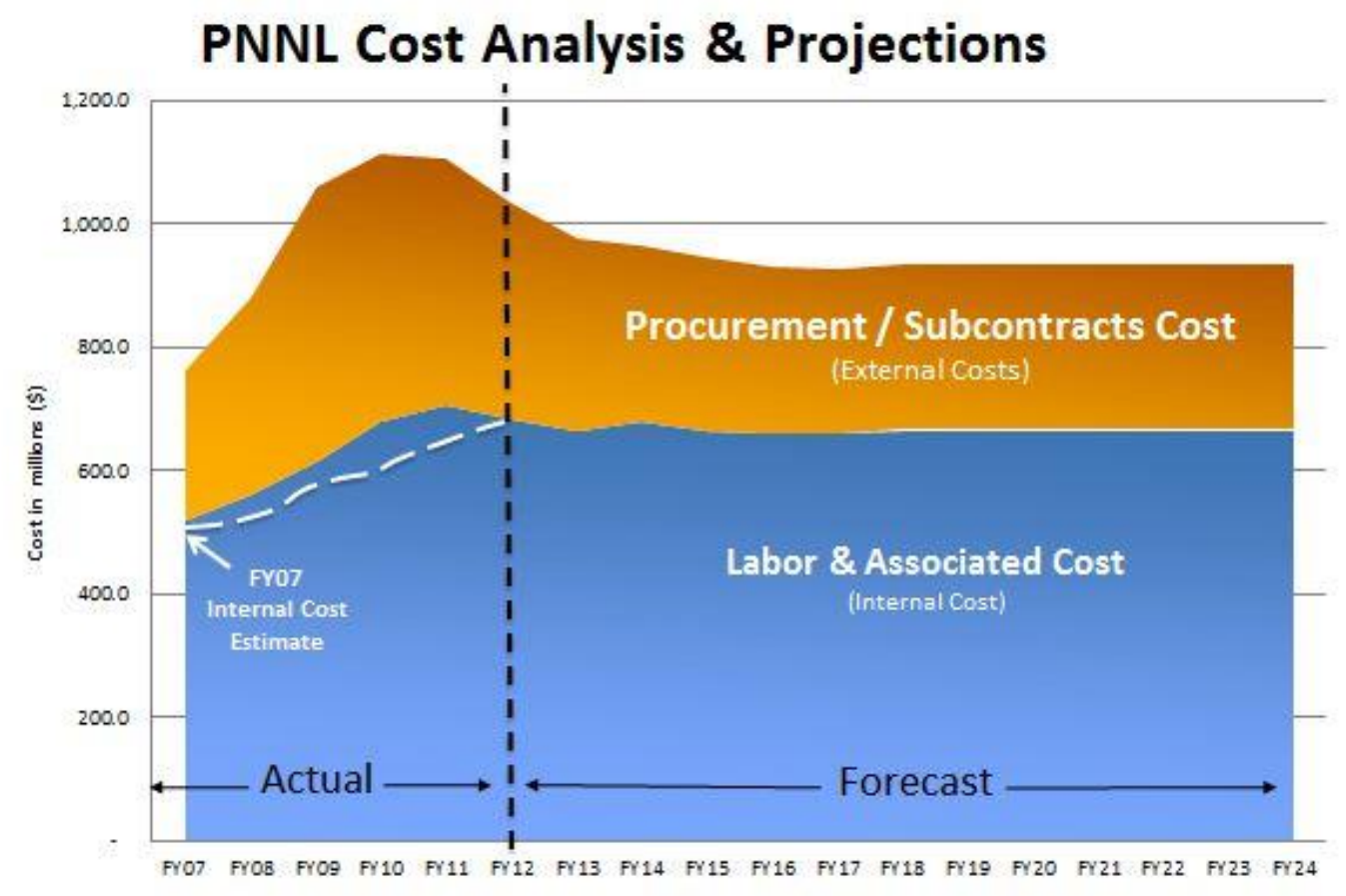

Figure 2: PNNL Cost Analysis \& Projections

Since future program needs drive the type of laboratory space required, a relatively stable 10-year funding forecast translates into a similar stable need for the type and quantity of space at the laboratory. Space planning is based on the forecast for the "Labor \& Associated Cost" or the internal costs. These costs are tied to the work that is done directly at the Laboratory. Space is determined by translating the cost into FTEs and then the FTEs into the type and amount of space they will need to do the work. PNNL has implemented an integrated capability management approach which provides the ability to map client 
funding to core capabilities, type of space, facilities and staff. Figure 3, Starlight View of Integrated Staff, Facilities, and Capabilities, is a visual representation of this integrated view. The highlighted example in Figure 3, shows that the funding (for fiscal year 2012) coming from the Office of Science funds 534 FTEs at PNNL. The 534 FTEs touch 1,950 staff across the laboratory and demonstrates the stewardship footprint SC and other clients have at PNNL. Mapping of this information results in a clearer understanding of the types and quantities of space that are used to meet client needs today. Based on anticipated flat projections and minimal changes in the type of work that will be done over the next 10 years it is expected that the same type (office and Laboratory) and quantity (functional square feet) of space will be needed. The current and projected space needs over the next 10 years is summarized in Table 1. Space types are further defined in Appendix F.
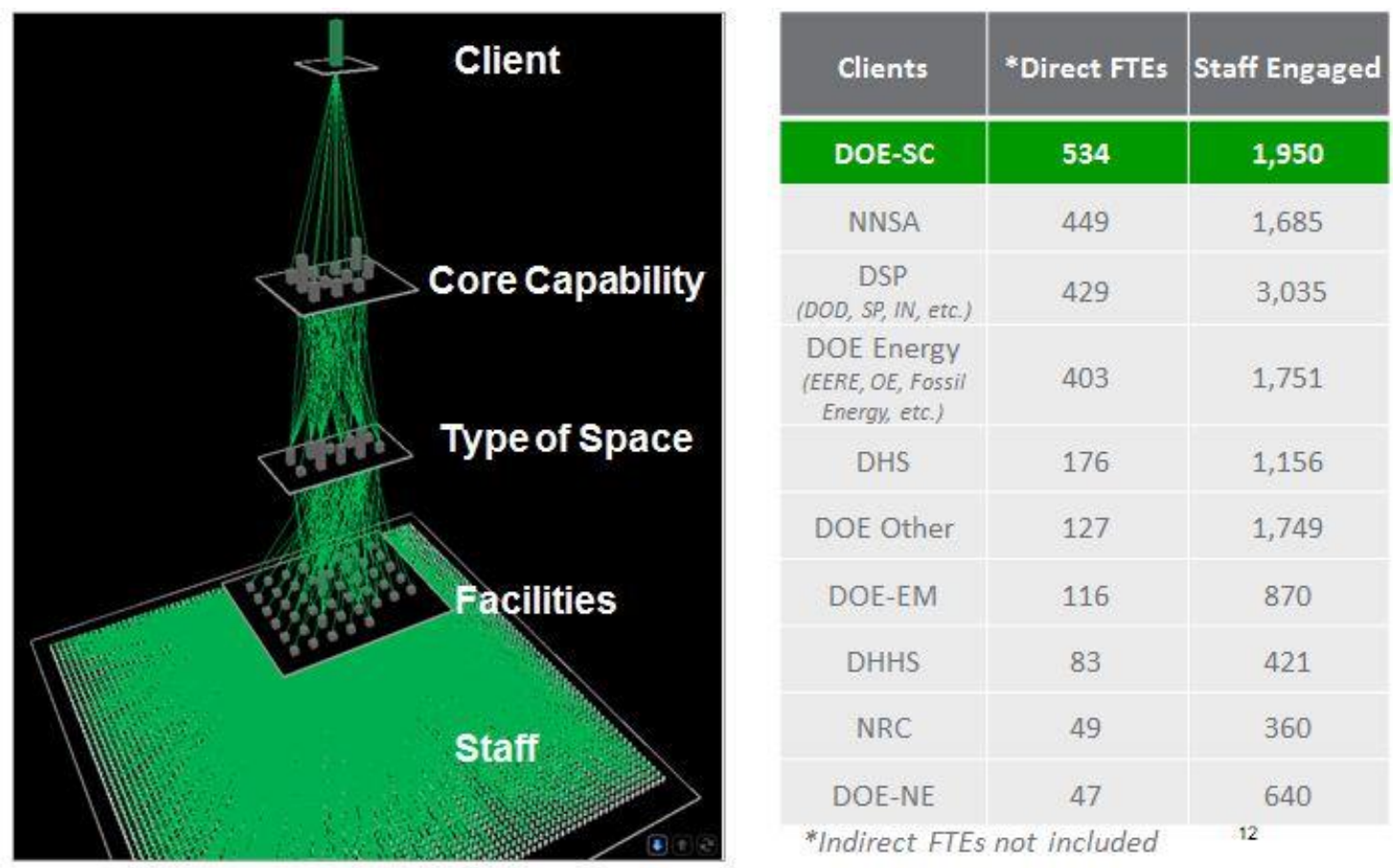

Figure 3: Starlight View of Integrated Staff, Facilities, and Capabilities

Table 1: Current/Projected Space Type Needs

\begin{tabular}{lr}
\hline Space Type & $\begin{array}{c}\text { Current/Projected Need } \\
\text { Functional Square Feet*** }\end{array}$ \\
Office & 576,000 \\
Biological/Procedure & 76,000 \\
Chemistry/Materials (Radiological) & 14,000 \\
Chemistry/Materials (Non-Radiological) & 71,000 \\
Computational & 54,000 \\
Instrumentation & 145,000 \\
Laboratory Support & 63,000 \\
Imaging & 8,000 \\
Other & 53,000 \\
$* *$ Functional Square Feet - & \\
\hline
\end{tabular}


The integrated capability management concept is further demonstrated in Figures 4, PNNL Facilities Support Multiple Clients. In general, staff located in the facilities use their expertise to address the needs of multiple clients (Figure 4). With the exception of the user portion of the Environmental Molecular Sciences Laboratory (EMSL), all clients support (through an indirect charge) the operation and maintenance of the facilities.

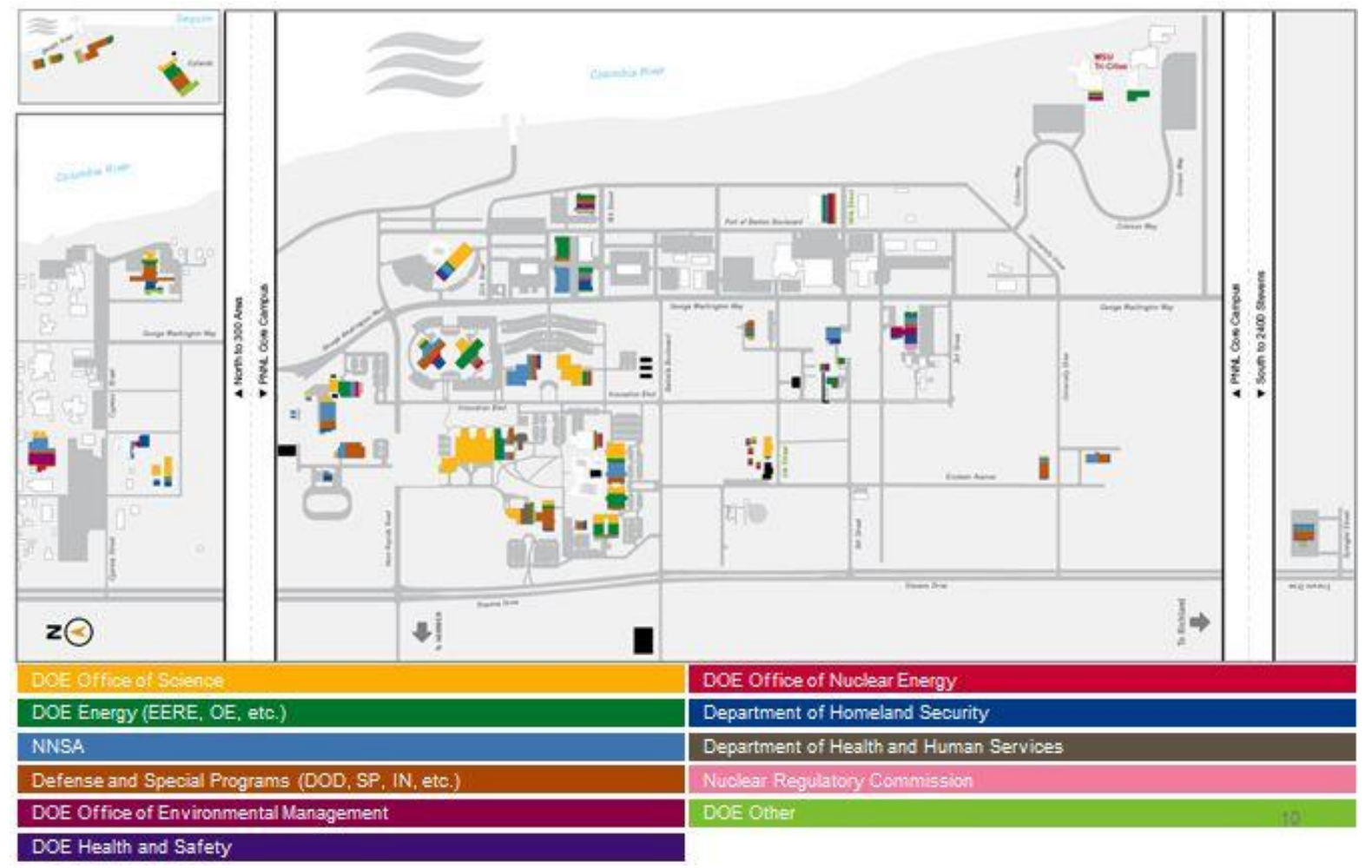

Figure 4: PNNL Facilities Support Multiple Clients

\subsection{Client Validation Results}

Table 2 summarizes the results of the input received from PNNL clients with respect to the four questions that where discussed with them. Overall, all clients clearly articulated capabilities which span across basic to applied research. Clients indicated across the board that they in part go to PNNL for their respective capabilities because they are world leading, unique and are synergistic with other capabilities and programs. In addition, many clients highlighted PNNL's responsiveness and abilities related to project management integration. All clients indicated that the work PNNL performs (in the areas noted in questions 1 and 2) is central to their missions. Finally, all clients indicated that they anticipate a relatively flat funding level for PNNL over the next 5-10 years. Client input, consolidated by each question, is contained in the following appendices; Question 1 is in Appendix G, Question 2 is in Appendix H, Question 3 is in Appendix I and Question 4 is in Appendix J. 
Table 2: Client Validation Summary

\begin{tabular}{|c|c|c|c|c|c|c|c|c|}
\hline & $\frac{\underline{r}}{\stackrel{1}{\oplus}}$ & 壯 & 全 & 芯 & $\frac{\sqrt[1]{2}}{\frac{1}{|r|}}$ & $\frac{\bar{\Xi}}{\overline{0}}$ & $\stackrel{2}{\frac{\pi}{1}}$ & $\sum_{I I}$ \\
\hline $\begin{array}{l}\text { Q1. Client Identified } \\
\text { Capabilities }\end{array}$ & $X$ & $\mathrm{X}$ & $\mathrm{X}$ & $\mathrm{X}$ & & $\mathrm{X}$ & & \\
\hline \multicolumn{9}{|l|}{ Q2. Why PNNL? } \\
\hline $\begin{array}{cl}\checkmark & \text { World Leading/ } \\
& \text { Completive Award }\end{array}$ & $X$ & $\mathrm{X}$ & $\mathrm{X}$ & $\mathrm{X}$ & & & & \\
\hline$\checkmark \quad$ Unique capability & $X$ & $X$ & $\mathrm{X}$ & $\mathrm{X}$ & & $\mathrm{X}$ & & \\
\hline $\begin{array}{ll}\checkmark & \text { Synergy with other } \\
\text { capabilities/programs }\end{array}$ & $X$ & $X$ & $\mathrm{X}$ & $\mathrm{X}$ & & $\mathrm{X}$ & & \\
\hline $\begin{array}{l}\checkmark \quad \text { Staff, equipment, } \\
\text { facilities }\end{array}$ & $X$ & $X$ & & $\mathrm{X}$ & & & & \\
\hline $\begin{array}{ll}\checkmark & \text { Industry/market } \\
\text { knowledge, emphasis on } \\
\text { commercialization }\end{array}$ & $\mathrm{X}$ & $X$ & & $\mathrm{X}$ & & & & \\
\hline $\begin{array}{ll}\checkmark & \text { Long standing } \\
& \text { relationships }\end{array}$ & $X$ & $\mathrm{X}$ & & $\mathrm{X}$ & & & & \\
\hline $\begin{array}{l}\checkmark \text { Project management/ } \\
\text { responsiveness }\end{array}$ & $X$ & $X$ & & $\mathrm{X}$ & & $\mathrm{X}$ & & \\
\hline$\checkmark$ Good value/low cost & $X$ & & & $\mathrm{X}$ & & & & \\
\hline Q3. Central to the mission & $\mathrm{X}$ & $X$ & $\mathrm{X}$ & $\mathrm{X}$ & & $\mathrm{X}$ & & \\
\hline $\begin{array}{l}\text { Q4. Validated Contractor } \\
\text { Forecast }\end{array}$ & $X$ & $X$ & $\mathrm{X}$ & $\mathrm{X}$ & & $\mathrm{X}$ & & \\
\hline
\end{tabular}

\subsection{Conclusion}

Validation of the Contractor's forecast by the clients provides confidence that the type of space needed over the next ten years will remain fairly consistent with the Laboratories current space types/capabilities. 


\section{Appendix C}

\section{Facility Economic Analysis Summary}




\section{Appendix C}

\section{Facility Economic Analysis Summary}

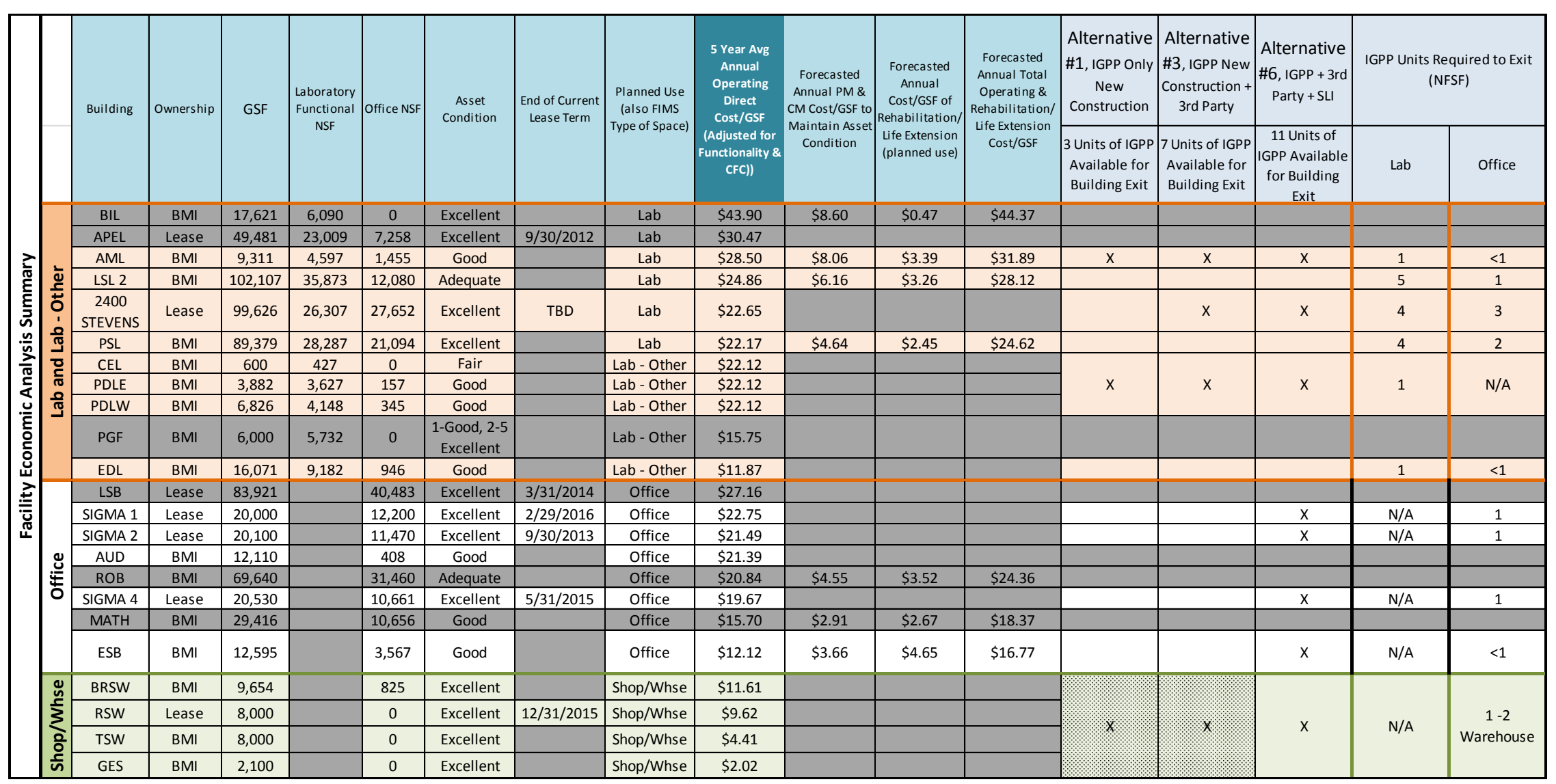

The facility economic analysis table summarizes the facility square footage, the type of space, the five year average annual operating costs with anticipated future maintenance and rehabilitation costs. The table was used to prioritize the facilities to exit in support of increasing federal facility control and is discussed in Section 2.2. 


\section{Appendix D}

\section{Alternative Mass Balance}




\section{Appendix D}

\section{Alternative Mass Balance}

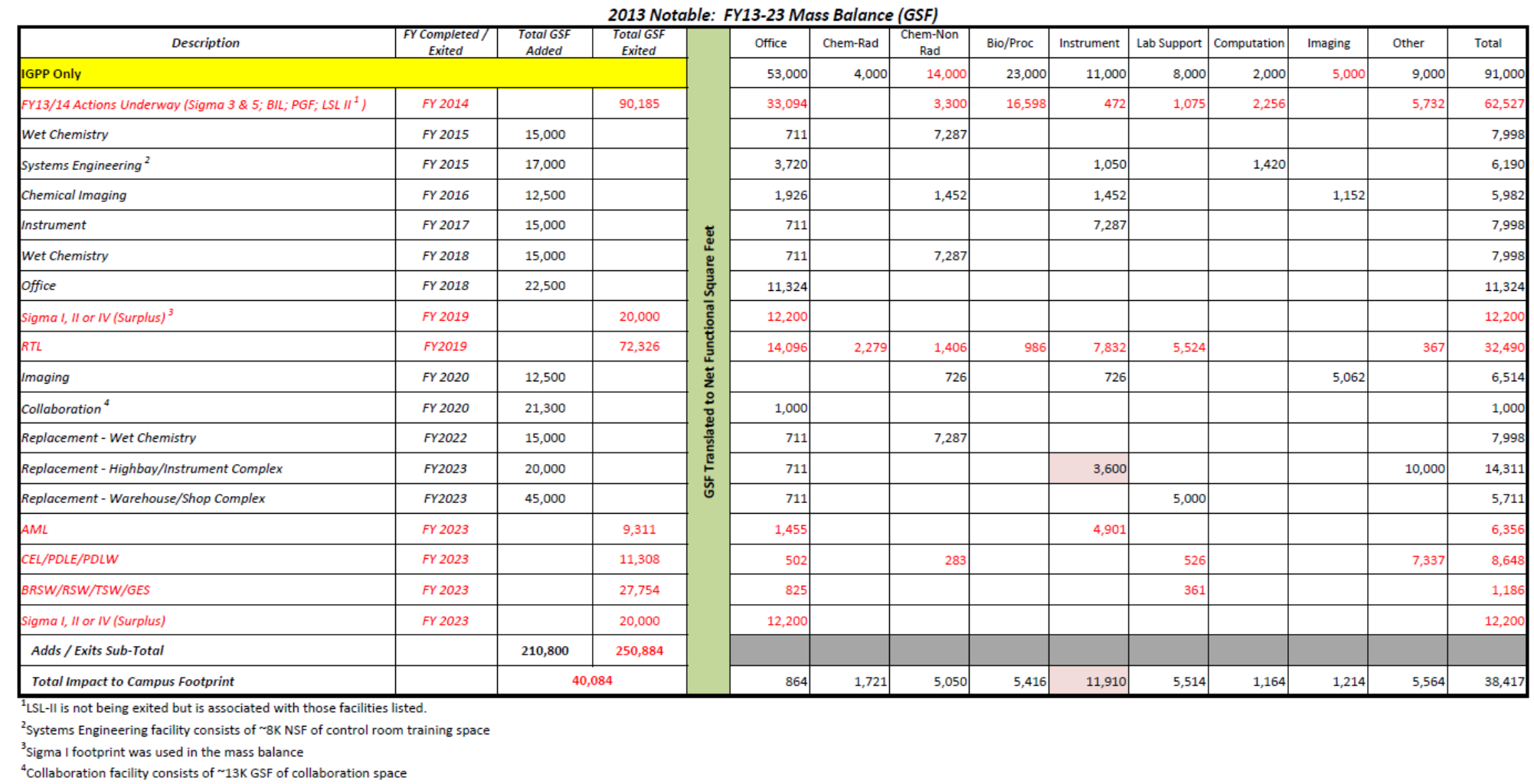




\section{Notable: FY13-23 Mass Balance (GSF)}

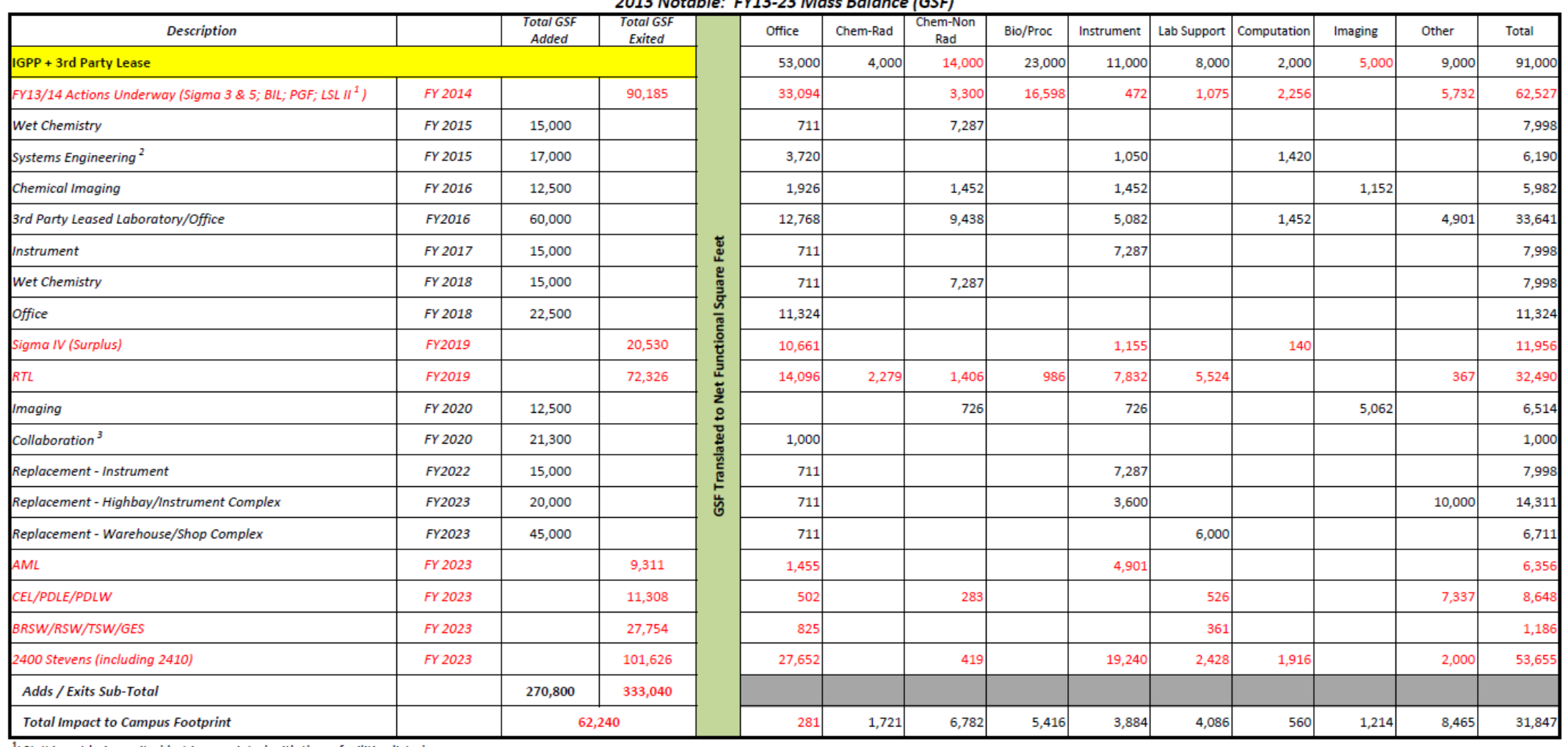

${ }^{1}$ LSL-II is not being exited but is associated with those facilities listed.

${ }^{2}$ Systems Engineering facility consists of $~ \$ \mathrm{~K}$ NSF of control room training space

${ }^{3}$ Collaboration facility consists of $~ 13 \mathrm{~K} \mathrm{GSF}$ of collaboration space 
2013 Notable: FY13-23 Mass Balance (GSF)

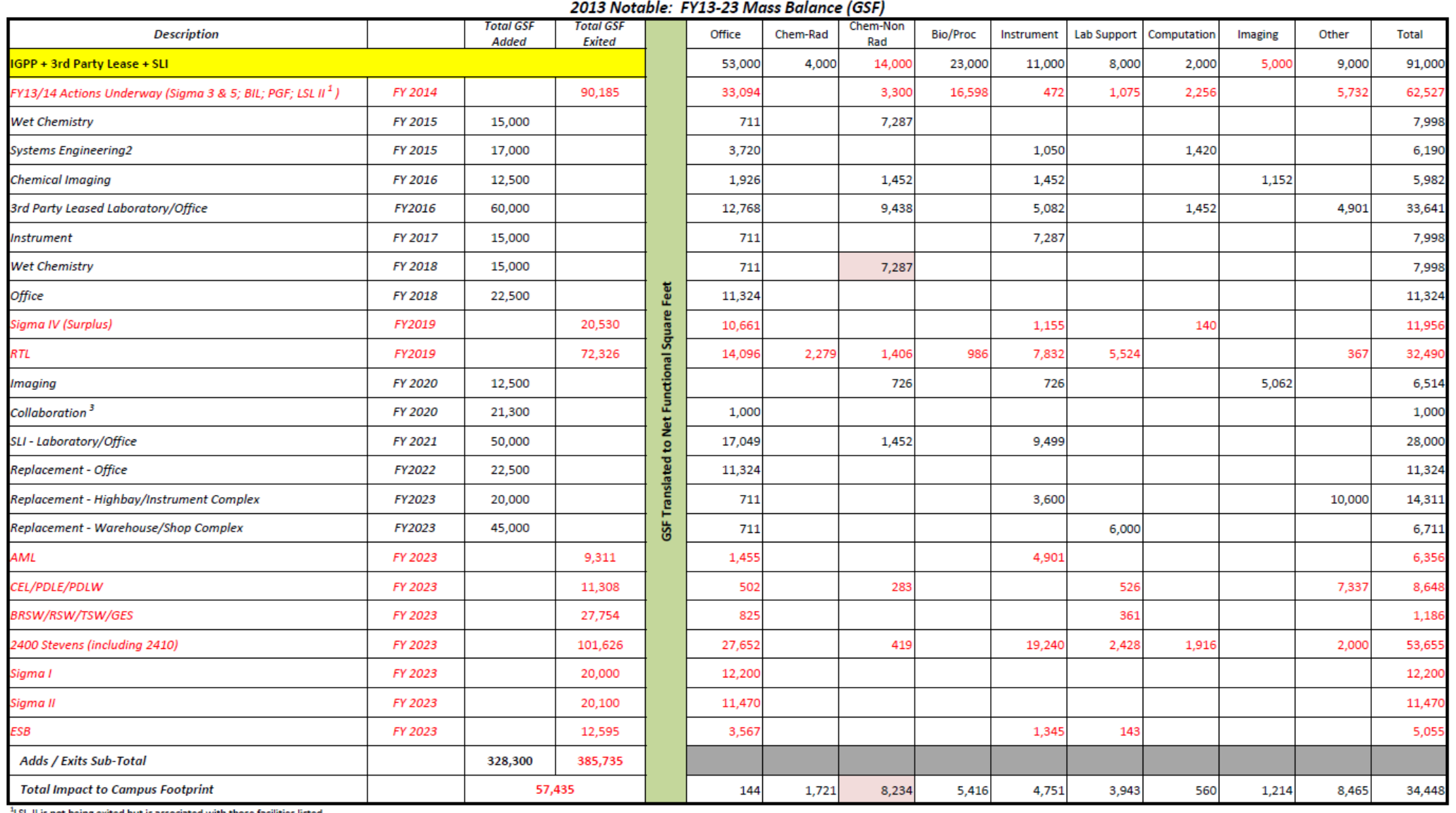

Total Impact to Campus Footprint

8,234

4,751

3,943

"Collaboration facility consists of $\sim 13 \mathrm{~K}$ GSF of collaboration space 
2013 Notable: FY13-23 Mass Balance (GSF)

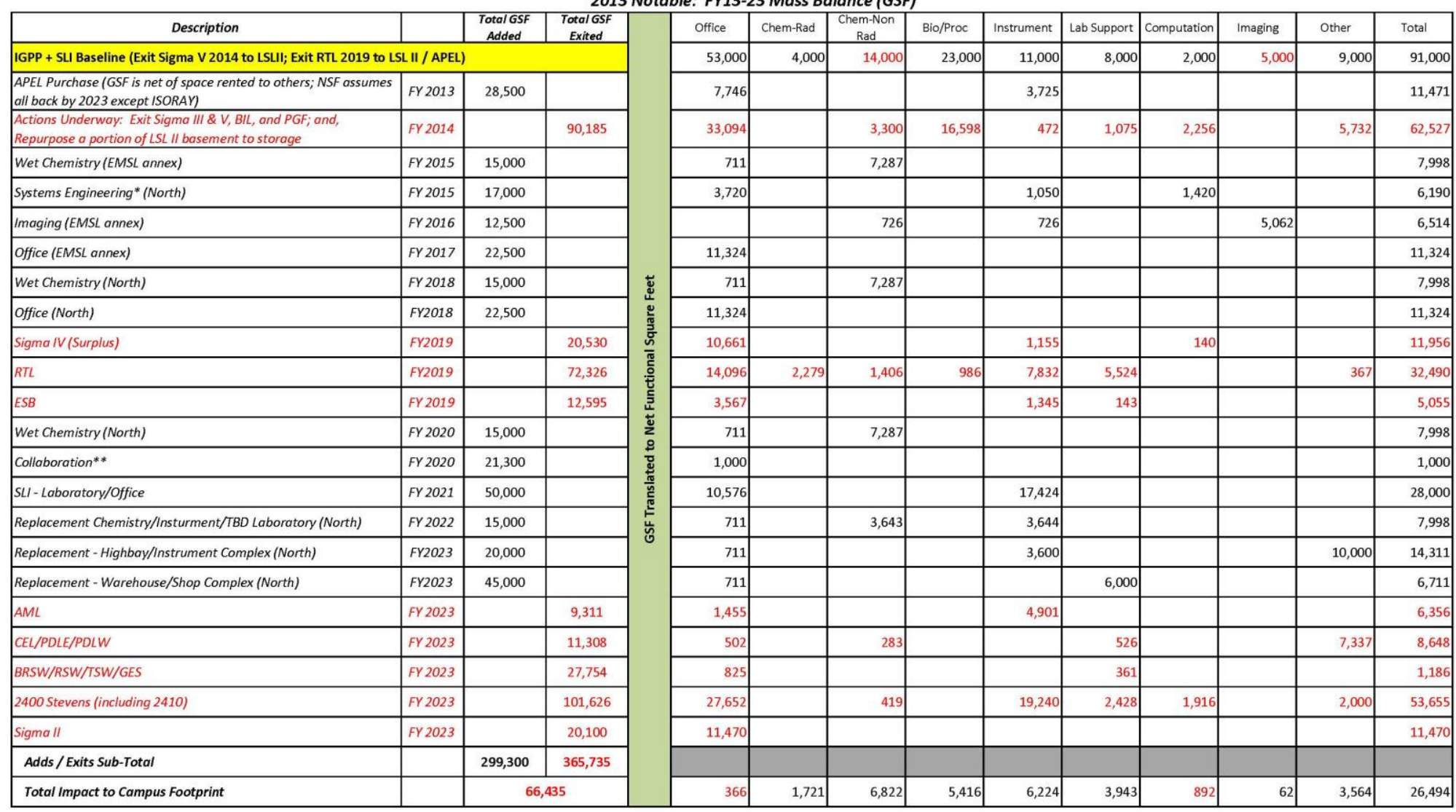




\section{Appendix E}

\section{Life Cycle Cost Analysis Methodology}




\section{Appendix E}

\section{Life Cycle Cost Analysis Methodology}

The analysis was performed per ADM-CM-055, PG-02 Alternative Analysis Development Process Guide section 3.1.1 Life Cycle Cost Analysis and meets the required intent of DOE O 413.3B Program and Project Management for the Acquisition of Capital Assets that the recommended alternative should, "...provide the essential functions and capabilities at an optimum life cycle cost, consistent with required cost, scope, schedule, performance, and risk consideration...reflected in the site's long-range planning documents..."

The life cycle cost analysis (LCCA) estimates the overall cost of viable alternatives on a comparable level to identify the lowest cost option that delivers the required scope. In order to achieve this, the LCCA identifies, assesses, and compares financial considerations of each viable alternative.

The list of viable alternatives presented for the Alternatives Analysis and that requires inclusion within the LCCA are as follows:

- Alternative 1 - IGPP Construction

- Alternative 2-IGPP \& Third Party Lease

- Alternative 3 - IGPP, Third Party Lease and SLI

- Alternative 4 - IGPP \& SLI.

In relation to this analysis, costs considered include:

- Construction - initial cost of capital required to construct the facility

- Direct O\&M

- New Facilities - forecasted, direct O\&M cost per GSF, based on facility type and ownership against the 5-year average of like spaces within the existing Building and Utilities (B\&U) pool

- Existing Facilities - actual direct O\&M cost per GSF, based on the 5-year average and adjusted for the CFC.

- Office Moves - cost per GSF to relocate offices from one facility to another

- Lab Moves - cost per GSF to relocate laboratory equipment from one facility to another

- Other Project Costs (OPC) - estimated cost for planning, permitting, conceptual design, solicitation, and transition to operations 
- Demolition - estimated cost to remediate radiological contamination and facility demolition

- Vacated Space - cost savings associated with exiting existing facilities in the form of direct O\&M and lease costs

- Lease - estimated annual payments associated with acquiring a new third party facility.

The acquisition methodology for each alternative dictated the pace to which scope was planned for execution. Acquisition costs were bounded by DOE guidance for each planning scenario:

\section{- $\operatorname{IGPP}(<\$ 10 \mathrm{M})$}

- $\quad$ SLI Line Item $(<\$ 100 M)$, not before 2019

- $\quad$ Third Party Lease ( $<\$ 50 \mathrm{M}$, sum of lease payments plus tenant improvements).

When new construction is complete or a lease is obtained, the direct O\&M costs begin to be incorporated within the study. For new facilities and leases, direct O\&M costs will be based on ownership and facility type against the 5-year average of like spaces within the direct B\&U pool.

Only facilities affected by an alternative were included within the study. For existing facilities, the 5year average of direct O\&M cost for each particular facility was used against the GSF of the facility for annual O\&M costs through the study period. As facilities were vacated, a credit was realized in the succeeding years for successfully vacating a space.

Each viable case was built in ECONPACK, a software package developed by USACE for use in the development of economic analysis in support of Department of Defense funding requests, and compared to one another for a full mission requirements analysis.

The period of analysis selected for this study was 30 years, with 2014 being the base year. A 30 year study period was chosen for four distinguishing factors:

- 30 years is an adequate time to ensure the run-time of the various cost strings are sufficiently included and properly analyzed for each alternative on a comparable basis.

- Lease options that contain an underlying ground lease, similar to the Biological Sciences Facility/Computational Sciences Facility, require a 30-year period to understand the impacts associated with either continuing the lease or abandoning the facility in place (change of ownership).

- If using a10-year period, insufficient time would be allotted to account for the direct O\&M costs associated with each alternative, which is a primary driver within the study.

- A 50-year period is acceptable and inclusive of all costs, but over the longer period the string of costs would not vary significantly. Assumptions would have to be incorporated into the alternatives containing leases to understand how the lease structure would be handled over an extended period of time, which may or may not inadvertently impact the results of the analysis. 
A constant-dollar analysis based on the real interest rate was used for the LCCA to eliminate the uncertainty of escalation. Below is a forecast of real interest rates obtained from OMB Circular A-94, Appendix C (December 2012 revision), which is based on the economic assumptions from the 2014 Budget, with the inflation premium removed. These real rates will be used for discounting constantdollar flows, as is often required in cost-effectiveness analysis.

Real Interest Rates on Treasury Notes and Bonds of Specified Maturities (in percent)

$\begin{array}{cccccc}3 \text {-Year } & 5 \text {-Year } & \text { 7-Year } & 10 \text {-Year } & \text { 20-Year } & \text { 30-Year } \\ -1.4 & -0.8 & -0.4 & 0.1 & 0.8 & 1.1\end{array}$

Through the course of the study a decision was made to implement the premise of the IGPP Construction alternative as the base for each alternative to be analyzed, with the individual facility type changing based on type of space provided with the addition of the third party Lease, the SLI line item, or a combination thereof. Due to the varying degrees of variability between each alternative, an "apples to apples" comparison is not achievable without breaking the net present value of each alternative into a cost per GSF built; therefore, the recommended alternative will be the one that displays the lowest NPV per GSF built. Non-monetary considerations were not taken into account within the LCCA, as the merits of those topics are addressed in the over-arching alternatives analysis.

\section{Enabling Assumptions:}

1. Study Period $=30$ Years, Base Year $=2014$

2. Constant-Dollar Analysis based on the real interest rate of 1.1 percent per OMB Circular A94, Appendix C (December 2012 Revision) (http://www.whitehouse.gov/omb/circulars_a094/a94_appx-c)

3. For new facilities and leases, direct O\&M costs based on ownership and facility type against the 5-year average of like spaces within the direct B\&U pool. Assumes O\&M costs begin the FY after construction completion in all cases. Annual facility O\&M costs based on GSF.

- Assumed O\&M Costs for new DOE Office, Lab, and Warehouse Space:

○ New DOE Office: $\$ 12.79 /$ GSF

o New DOE Laboratory: \$16.57/GSF

o New DOE Warehouse: \$6.06/GSF

- Assumed O\&M Costs for new Leased Lab Spaces:

○ New Lease Laboratory: \$5.44/GSF (lease cost captured separately). 
4. Move costs (laboratory and office) based on net functional square feet (NFSF). Cost per square foot based on parametric estimates:

- Office Moves: \$16.67/NFSF

- Laboratory Moves: $\$ 27.41 / \mathrm{NFSF}$

- Move costs are included within each new facility

- Move costs are applied to vacating existing space only when those facilities are being absorbed by surplus space.

5. Third Party construction cost estimated per GSF based on parametric data:

- Assumes developer's financing over 25-year term at 5.7 percent interest, per OSD business office manager.

- Soft costs of 28.93 percent (based on BSF model) account for developer fees, design, contingency, financing, bond insurance, and placement fees.

- PV sum of initial term payments cannot exceed 90 percent of the capital amount.

- Assumed 14-year lease term with 11-year tail based on PV of rental payments. PV of rental payments based on 30-year nominal interest rate as defined by OMB Circular A-94, Appendix C (December 2012 Revision) (http://www.whitehouse.gov/omb/circulars_a094/a94_appx-c).

6. 10-year investment amounts only include capital funds pertaining to IGPP and SLI actions.

7. After RTL is vacated, assumed $\$ 364,095 /$ year O\&M until remediation is finalized based on estimate provided by the OSD Business Office.

8. For "Sigma I, II, or IV Surplus" exits (IGPP Construction), the average rate of $\$ 22.33 /$ GSF to compute vacated space savings was used.

9. OPC for SLI construction based on percent of OPC against the Physical Sciences Facility construction (\$9.113M PSF OPC/\$174.879M PSF Construction) $=5.2$ percent.

10. OPC for IGPP projects based on value estimated for CIL ( $\$ 260 \mathrm{~K}$ total) split evenly over the construction period. 


\section{Appendix F}

\section{Alternative Waterfall Schedules}




\section{Appendix F}

\section{Alternative Waterfall Schedules}

\begin{tabular}{|c|c|c|c|c|c|c|c|c|c|c|c|c|c|c|}
\hline Description & Total GSF & $\begin{array}{c}\text { Total cost } \\
\text { (SM) }\end{array}$ & 2014 & 2015 & 2016 & 2017 & 2018 & 2019 & 2020 & 2021 & 2022 & 2023 & & \\
\hline \multicolumn{13}{|l|}{ IGPP Only Scenario New Construction } & & \\
\hline Wet Chemistry & 15,000 & $\$ 9.5$ & $\$ 5.5$ & $\$ 4.0$ & & & & & & & & & & \\
\hline Systems Engineering & 17,000 & $\$ 9.5$ & $\$ 6.5$ & $\$ 3.0$ & & & & & & & & & & \\
\hline Chemical Imaging & 12,500 & $\$ 9.5$ & & $\$ 5.0$ & $\$ 4.5$ & $\triangle$ & & & & & & & & \\
\hline Instrument & 15,000 & $\$ 9.5$ & & & $\$ 7.5$ & $\$ 2.0$ & & & & & & & & \\
\hline Wet Chemistry & 15,000 & $\$ 9.5$ & & & & $\$ 5.5$ & $\$ 4.0$ & CHEM & TRY GAP F & & & & & \\
\hline Office & 22,500 & $\$ 9.5$ & & & & $\$ 4.5$ & $\$ 5.0$ & & $\triangle$ & \multicolumn{3}{|l|}{ Exit RTL } & \multicolumn{2}{|c|}{$\triangle$ Imaging Milestone } \\
\hline Imaging & 12,500 & $\$ 9.5$ & & & & & $\$ 3.0$ & $\$ 5.0$ & $\$ 1.5$ & & & & $\Delta$ & RTL Exit Milestone \\
\hline Collaboration & 21,300 & $\$ 9.5$ & & & & & & $\$ 3.0$ & $\$ 6.5$ & & & & & \\
\hline Replacement: Wet Chemistry & 15,000 & $\$ 9.5$ & & & & & & & & $\$ 5.5$ & $\$ 4.0$ & & & \\
\hline Replacement: High Bay/Instrument & 20,000 & $\$ 9.5$ & & & & & & & & $\$ 2.5$ & $\$ 4.0$ & $\$ 3.0$ & & \\
\hline Replacement: Warehouse/Shop & 45,000 & $\$ 5.0$ & & & & & 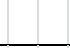 & ( & 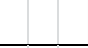 & & & $\$ 5.0$ & \multirow[t]{2}{*}{ Total: } & \\
\hline RTL Exit & $(72,326)$ & - & & & & & & 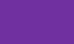 & & & & & & \\
\hline$A M L$ & $(9,311)$ & - & & & & & & & & & & . & & \\
\hline CEL/PDLE/PDLW & $(11,308)$ & - & & & & & & & & & & 2024 & & \\
\hline BRSW/RSW/TSW/GES & $(27,754)$ & - & & & & & & & & & & 2024 & & \\
\hline Sigma 1 & $(20,000)$ & - & P & 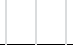 & 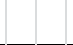 & +1 & 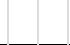 & 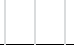 & 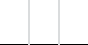 & t & 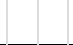 & . & & \\
\hline Annual F\&I Cost (M) & & & $\$ 12.0$ & $\$ 12.0$ & $\$ 12.0$ & $\$ 12.0$ & $\$ 12.0$ & $\$ 8.0$ & $\$ 8.0$ & $\$ 8.0$ & $\$ 8.0$ & $\$ 8.0$ & $\$ 100.0$ & \\
\hline
\end{tabular}




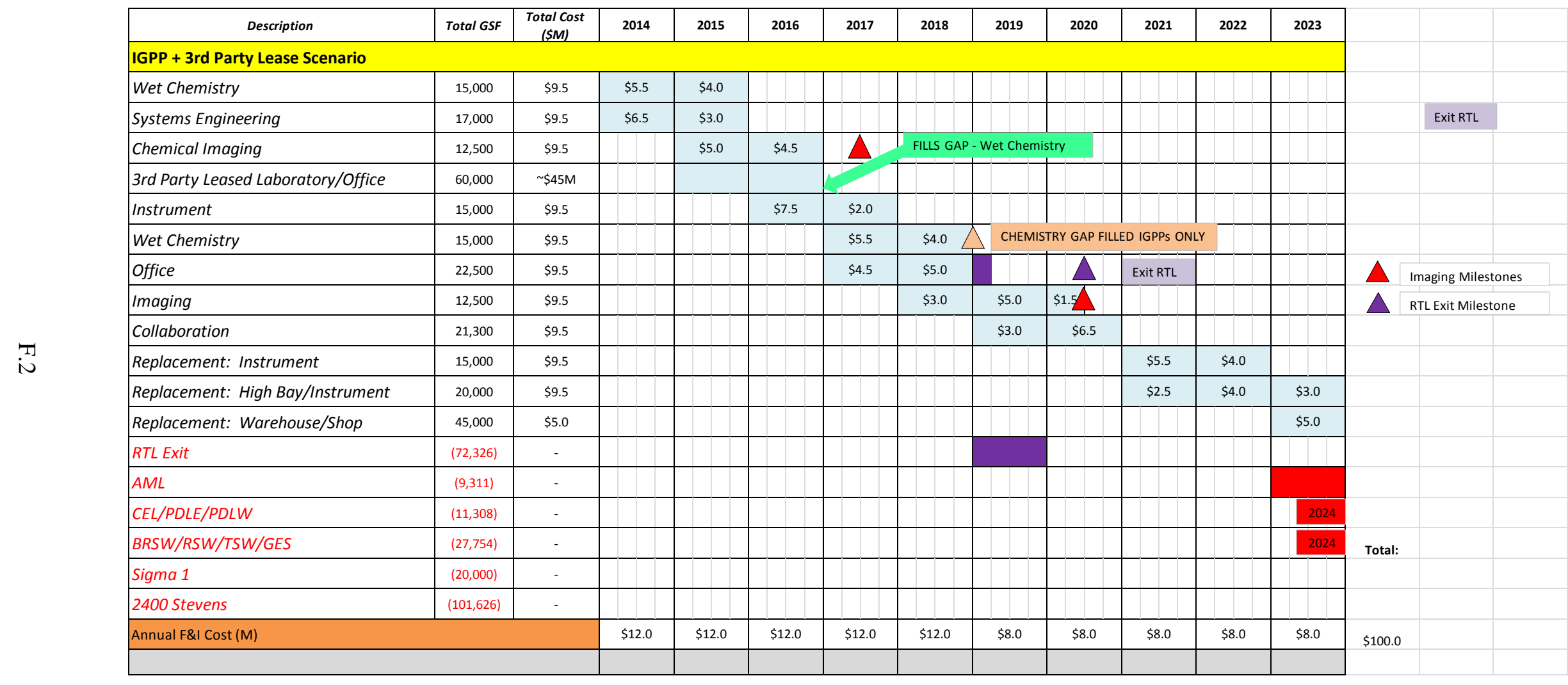




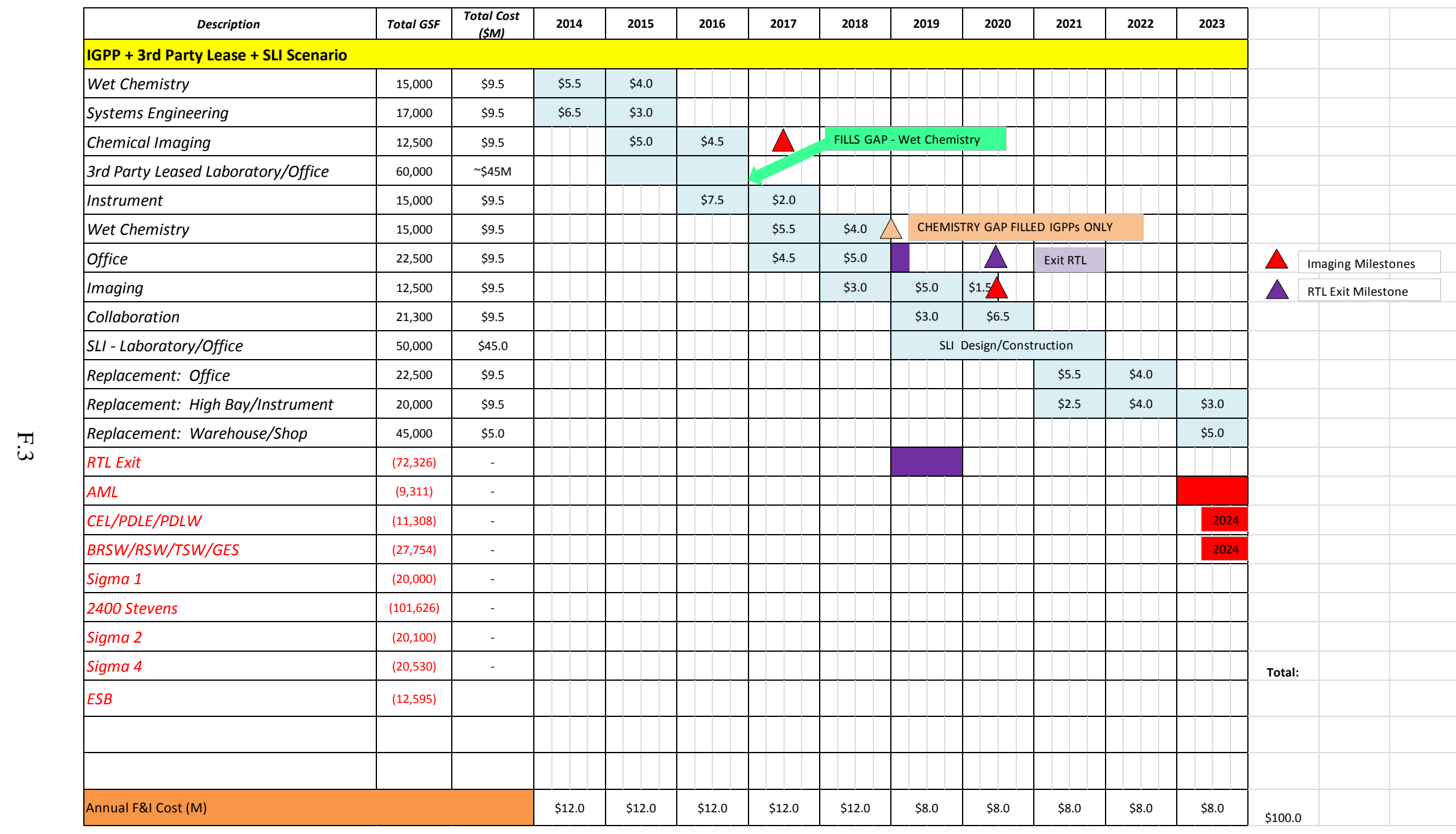




\begin{tabular}{|c|c|c|c|c|c|c|c|c|c|c|c|c|c|}
\hline \begin{tabular}{|c|} 
Description \\
\end{tabular} & Total GSF & $\begin{array}{c}\text { Total Cost } \\
(S M)\end{array}$ & 2013 & 2014 & 2015 & 2016 & 2017 & 2018 & 2019 & 2020 & 2021 & 2022 & 2023 \\
\hline \multicolumn{14}{|c|}{ IGPP + SLI Baseline (Exit Sigma V 2014 to LSL II; Exit RTL 2019 to LSL II/APEL) } \\
\hline APEL Purchase (GSF is net of space rented to others) & 28,500 & $\$ 7.0$ & $\$ 7.0$ & & & & & & & & & & \\
\hline Actions Underway (Exits \& Repurpose) & $(90,185)$ & - & & & & & & & & & & 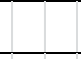 & \\
\hline Wet Chemistry (EMSL Annex) & 15,000 & $\$ 9.5$ & & $\$ 5.5$ & $\$ 4.0$ & & & & & & & & 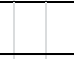 \\
\hline Systems Engineering & 17,000 & $\$ 9.5$ & & $\$ 6.5$ & $\$ 3.0$ & 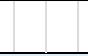 & & & & & & 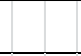 & \\
\hline Imaging (EMSL Annex) & 12,500 & $\$ 9.5$ & & & $\$ 5.0$ & $\$ 4.5$ & & & & & & & \\
\hline Office (EMSL Annex) & 22,500 & $\$ 9.5$ & & & & $\$ 7.5$ & $\$ 2.0$ & 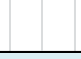 & & & & 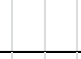 & \\
\hline Wet Chemistry (North) & 15,000 & $\$ 9.5$ & & & & & $\$ 5.5$ & $\$ 4.0$ & & & & 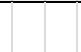 & 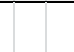 \\
\hline Office (North) & 22,500 & $\$ 9.5$ & & & & & $\$ 4.5$ & $\$ 5.0$ & & & & & \\
\hline Sigma 4 Exit & $(20,530)$ & - & & & & & & & & & & & \\
\hline RTL Exit & $(72,326)$ & - & & & & & & & & & & & \\
\hline ESB & $(12,595)$ & 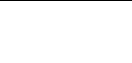 & & & & & & & & & & & \\
\hline Wet Chemistry (North) & 15,000 & $\$ 9.5$ & & & & & & $\$ 3.0$ & $\$ 5.0$ & $\$ 1.5$ & & 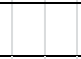 & 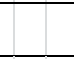 \\
\hline Collaboration & 21,300 & $\$ 9.5$ & & & & & & & $\$ 3.0$ & $\$ 6.5$ & & & \\
\hline SLI - Laboratory/Office & 50,000 & $\$ 45.0$ & & & 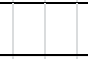 & & & & \multicolumn{3}{|c|}{ SLI Design/Construction } & & \\
\hline Replacement: Chem/Inst/TBD Lab (North) & 15,000 & $\$ 9.5$ & & & 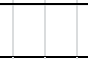 & & & & & & $\$ 5.5$ & $\$ 4.0$ & \\
\hline Replacement: High Bay/Instrument (North) & 20,000 & $\$ 9.5$ & & & 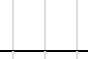 & & & & & & $\$ 2.5$ & $\$ 4.0$ & $\$ 3.0$ \\
\hline Replacement: Warehouse/Shop (North) & 45,000 & $\$ 5.0$ & & & 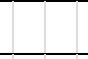 & 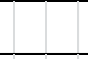 & & & & & & 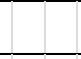 & $\$ 5.0$ \\
\hline AML Exit & $(9,311)$ & - & & & & & & & & & & & \\
\hline CEL/PDLE/PDLW Exit & $(11,308)$ & - & & & & & & & & & & 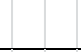 & 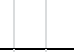 \\
\hline BRSW/RSW/TSW/GES Exit & $(27,754)$ & - & & & & & & & & & & & \\
\hline 2400 Stevens (including 2410) Exit & $(101,626)$ & - & & & t & & & & & & & 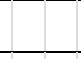 & \\
\hline Sigma 2 Exit & $(20,100)$ & - & & & & & & & & & & & \\
\hline Total Impact to Footprint & $(66,435)$ & & & & & & & & & & & & \\
\hline Annual F\&I Cost (M) & & & $\$ 7.0$ & $\$ 12.0$ & $\$ 12.0$ & $\$ 12.0$ & $\$ 12.0$ & $\$ 12.0$ & $\$ 8.0$ & $\$ 8.0$ & $\$ 8.0$ & $\$ 8.0$ & $\$ 8.0$ \\
\hline
\end{tabular}





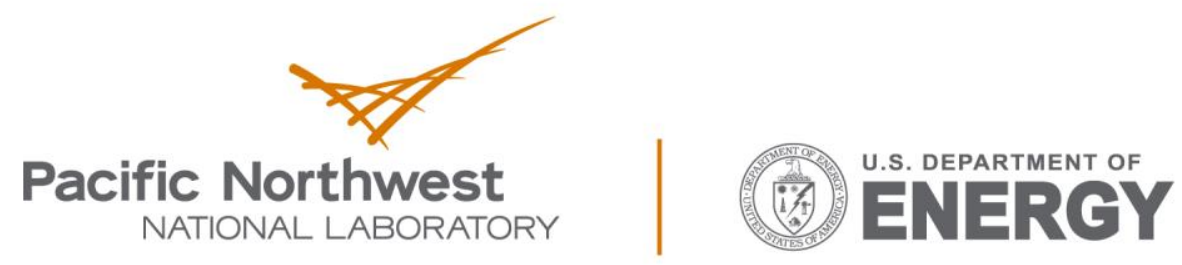

Proudly Operated by Battelle Since 1965

902 Battelle Boulevard

P.O. Box 999

Richland, WA 99352

1-888-375-PNNL (7665)

www.pnnl.gov 